Spring 2015

\title{
The "Squat-n-Swap": A Pilot Exercise Intervention to Promote Increased Physical Activity among Mothers of Young Children
}

\author{
Brook Skidmore \\ Western Washington University, skidmob@students.wwu.edu
}

Follow this and additional works at: https://cedar.wwu.edu/wwuet

Part of the Kinesiology Commons

\section{Recommended Citation}

Skidmore, Brook, "The "Squat-n-Swap": A Pilot Exercise Intervention to Promote Increased Physical Activity among Mothers of Young Children" (2015). WWU Graduate School Collection. 401.

https://cedar.wwu.edu/wwuet/401

This Masters Thesis is brought to you for free and open access by the WWU Graduate and Undergraduate Scholarship at Western CEDAR. It has been accepted for inclusion in WWU Graduate School Collection by an authorized administrator of Western CEDAR. For more information, please contact westerncedar@wwu.edu. 
The "Squat-n-Swap": A Pilot Exercise Intervention to Promote Increased Physical Activity among Mothers of Young Children

\author{
By \\ Brook Skidmore
}

Accepted in Partial Completion of the Requirements for the Degree Master of Science

Kathleen L. Kitto, Dean of the Graduate School

ADVISORY COMMITTEE

Chair, Dr. Linda Keeler

Dr. Gordon Chalmers

Dr. Keith Russell 


\section{Master's Thesis}

In presenting this thesis in partial fulfillment of the requirements for a master's degree at Western Washington University, I grant to Western Washington University the non-exclusive royalty-free right to archive, reproduce, distribute, and display the thesis in any and all forms, including electronic format, via any digital library mechanisms maintained by WWU.

I represent and warrant this is my original work, and does not infringe or violate any rights of others. I warrant that I have obtained written permission from the owner of any third party copyrighted materials included in these files.

I acknowledge that I retain ownership rights to the copyright of this work, including but not limited to the right to use all or part of this work in future works, such as articles or books. Library users are granted for individual, research and non-commercial reproduction of this work for educational purposes only. Any further digital posting of this document requires specific permission from the author.

Any copying or publication of this thesis for commercial purposes, or for financial gain, is not allowed without my written permission.

Signature: Brook Skidmore

Date: 04/20/2015 
The "Squat-n-Swap": A Pilot Exercise Intervention to Promote Increased Physical Activity among Mothers of Young Children

\author{
A Thesis \\ Presented to \\ The Faculty of \\ Western Washington University \\ In Partial Fulfillment \\ Of the Requirement for the Degree \\ Master of Science
}

By

Brook Skidmore

March, 2015 


\begin{abstract}
A large majority of mothers of young children are not sufficiently active to obtain health benefits, and motherhood itself has been associated with irregular physical activity. Ironically, however, a mother's demanding and busy life presents one of the most relevant opportunities for which exercise may be extremely advantageous. Therefore, the purpose of the current study was to determine the effectiveness of an exercise intervention for increasing physical activity levels and perceived social support for exercise among mothers of young children who serve as primary caregivers. Thirty one mothers with at least one child under the age of five were recruited to participate in the study. A treatment group $(n=16)$ participated in an instructor-led "Squat-nSwap" exercise program once per week for four weeks, followed by four weeks without instructor supervision. A control group $(n=15)$ did not participate in the exercise program. Participants completed a questionnaire before and after the study in order to assess their physical activity levels and perceived social support for exercise, and comparative analysis was used to evaluate the differences in pre to post-study levels of these variables. Mixed between-within groups ANOVAs with a significance of $p<0.05$ were used to analyze the data, as well as a chi square analysis. Post-hoc t-tests were conducted to determine the source of differences among statistically significant ANOVA interactions utilizing a Bonferroni correction of $p<.0125$. Cross tabs also revealed positive changes in women's perceptions of changes in their physical activity levels. Results also revealed significant interactions for support in the forms of childcare, information, companionship, and validation. The "Squat-N-Swap" model might be a useful option for mothers of young children who would benefit from social support to exercise; however, more research is needed to ascertain this program's effectiveness in increasing physical activity levels among this population.
\end{abstract}




\section{ACKNOWLEDGEMENTS}

I would like to express heartfelt appreciation to all of my professors at Western Washington University, and specifically to my thesis committee for their time, advice, wisdom, and patience throughout the duration of this project. Many thanks to Dr. Linda Keeler for her continuous mentorship and long hours, and for her willingness to provide constant encouragement and support while at the same time gently pushing me to reach past my comfort levels. Thanks to Dr. Gordon Chalmers for his time and assistance in helping me find and understand the best ways to analyze and interpret my results. Thanks to Dr. Russell for his wisdom, advice, and for his ability to make me feel confident and excited in undertaking something I had never before attempted. A big thank you to Alex, Matt, and Piper, the best classmates to be "stuck" with for two whole years! I would also like to thank my family for their unlimited support and love throughout every step of this project, especially my mom and sisters who exemplify to me what it means to be an amazing mother. Finally, and most importantly, though social psychologists might call it "magical thinking" and sport psychologists might call it "superstition," I would have to call it a "reality," and give my greatest appreciation to God, the underlying source of anything that was successful in this project. 


\section{TABLE OF CONTENTS}

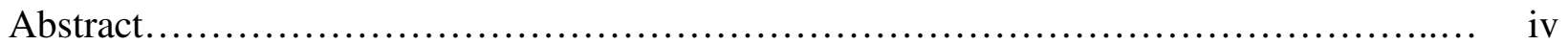

Acknowledgements...................................................... v

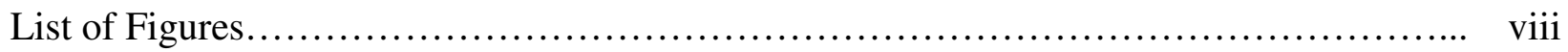

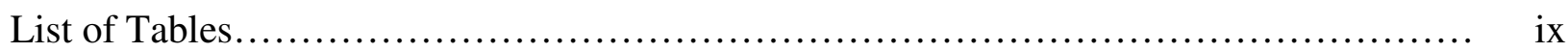

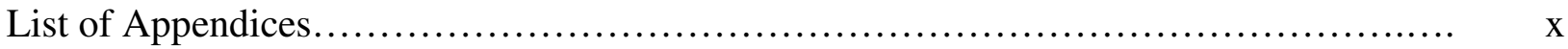

CHAPTER I THE PROBLEM AND ITS SCOPE

Introduction....................................... 1

Purpose of the Study................................ 2

Hypothesis......................................... 2

Significance of the Study............................ 2

Limitations of the Study........................... 3

Definition of Terms................................. 4

CHAPTER II REVIEW OF LITERATURE

Introduction...................................... 6

Benefits of Exercise for Women........................ 6

Perceived Barriers to Exercise among Mothers ........... 12

Interventions for Exercising Mothers................. 23

Practical Strategies of Regular Exercising Mothers........ 29

Summary $\ldots \ldots \ldots \ldots \ldots \ldots \ldots \ldots \ldots \ldots \ldots \ldots \ldots \ldots \ldots \ldots, \quad 44$

CHAPTER III METHODS AND PROCEDURES

Introduction..................................... 45

Description of Study Population....................... 45 
Design of the Study................................. 45

Data Collection Procedures............................ $\quad 46$

Data Analysis............................................ 51

CHAPTER IV RESULTS AND DISCUSSION

Results.......................................... 52

Discussion............................................ $\quad 59$

CHAPTER V Summary, Conclusion, and Recommendations

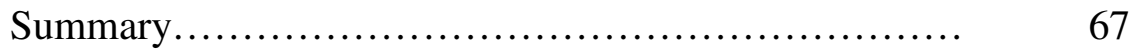

Conclusion........................................... 67

Recommendations................................. 68

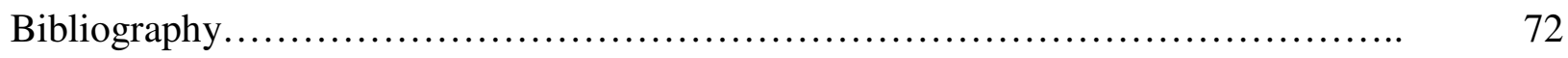

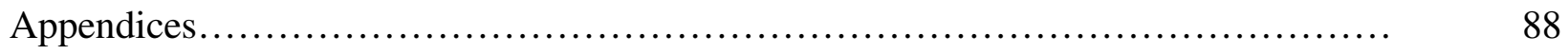




\section{LIST OF FIGURES}

Figure 1. The social ecological model........................................ 42

Figure 2. Means and Standard Deviations for Perceived Social Support for Exercise.... 


\section{LIST OF TABLES}

Table 1. Participant Characteristics...................................... 46

Table 2. Means and Standard Deviations for Self-Reported Sessions of Physical Activity in

Previous Week .................................................. 53

Table 3. Frequencies for Perceived Change in Physical Activity in the Past 8 Weeks-Treatment

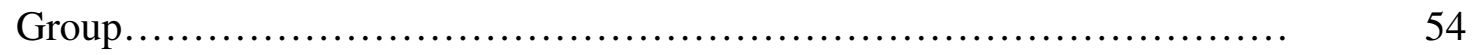

Table 4. Frequencies for Perceived Change in Physical Activity in the Past 8 Weeks- Control

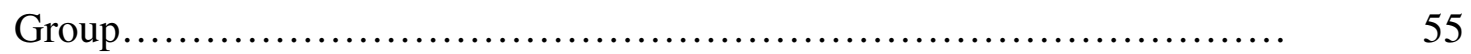

Table 5. Means and Standard Deviations for Perceived Social Support for Exercise at Pre and

Post.................................................................... 


\section{LIST OF APPENDICES}

Appendix A. 7-day Recall Questionnaire...................................... 88

Appendix B. Social Support for Exercise Questionnaire........................... 89

Appendix C. Demographics Questions...................................... 92

Appendix D. Additional Post-Intervention Qualitative Questions..................... 93

Appendix E. Informed Consent Form for Treatment Participants................... 95

Appendix F. Informed Consent Form for Control Participants..................... 98

Appendix G. Recruitment Email for Treatment Group......................... 101

Appendix H. Recruitment Email for Control Group.......................... 104

Appendix I. Outline for Treatment Group Introductory Workshop................ 106

Appendix J. Outline of Workout for Exercise Intervention ..................... 107

Appendix K. Outline of Exercise Psychology Principles Discussed during Cooldown

Portion of Workouts.................................................... 108 


\section{Chapter I}

\section{The Problem and Its Scope}

\section{Introduction}

There is an undeniable link between women who exercise regularly and positive health effects (Garber et al., 2011). Yet an alarming majority of women are not active enough to meet even the minimum recommendations to obtain those health benefits (Scharff, Homan, Kreuter, \& Brennan, 1999; United States Department of Health and Human Services, 2000). This problem is notable among females when they are primary caregivers of young children (Brown, Brown, Miller, \& Hansen, 2001). In fact, motherhood itself has been noted as a risk factor for irregular physical activity (Brown et al., 2001; Hamilton \& White, 2010; Verhoef \& Love, 1994; Verhoef, Love, \& Rose, 1992). Primary caregivers who are female may be at greater risk of inactivity, as women are generally less active than men in westernized cultures (Lox, Martin Ginis, \& Petruzzello, 2010). ${ }^{1}$ Mothers of young children have listed numerous obstacles that they perceive as preventing them from being active (Brown et al., 2001; Hamilton \& White, 2011; Harrington, Dawson, \& Bolla, 1992; Netz, Zeev, Arnon, \& Tenenbaum, 2008; Thomsson, 1999; Verhoef \& Love, 1994). And yet, the demanding and stressful nature of a mother's daily life most certainly presents an ideal setting where the positive physical and mental health benefits of exercise could be realized to their fullest (Verhoef et al., 1992). Numerous exercise interventions have been proposed to address the unique needs of mothers of young children (e.g., Armstrong \& Edwards, 2003; Cody \& Lee, 1999; Cramp \& Brawley, 2006; Currie, 2004; Currie \& Develin, 2002;

Develin \& Currie, 2000; Fahrenwald, Atwood, Walker, Johnson, \& Berg, 2004; Haruna et al., 2013; Miller, Trost, \& Brown, 2002; Norman et al., 2010; Taveras et al., 2011); however, researchers have found mixed results. One potential solution that has been noted as an

\footnotetext{
${ }^{1}$ It should be noted that there is no known literature on male primary caregiver's physical inactivity risk.
} 
anecdotally effective strategy to increase exercise among women with young children is cooperating with other mothers, so that mothers take turns watching children while the other mothers exercise (Brown et al., 2001; Spowart et al., 2008; Spowart et al., 2010); however, this specific intervention has not yet been empirically tested. In addition, very few studies have included resistance training as part of the intervention, which is an essential component of a woman's overall conditioning program (e.g., Cody \& Lee, 1999; Develin \& Currie, 2000; Haruna et al., 2013). It appears that in order to be effective for this widely variable population, an exercise intervention for mothers of young children should address multiple factors, including allowing for flexibility, addressing childcare needs, and being time and cost-efficient. Efforts to encourage mothers' participation in physical activity would do well to empower mothers to overcome what they perceive as barriers so that regular exercise can become an integral part of their lifestyle.

\section{Purpose of the Study}

The purpose of this study was to determine the effectiveness of an eight-week exercise intervention called the "Squat-n-Swap," for increasing physical activity levels and perceived social support for exercise among mothers of young children who serve as primary caregivers.

\section{Hypothesis}

Following participation in an eight-week "Squat-n-Swap" exercise intervention, mothers of young children will have significantly greater levels of physical activity and perceived social support for exercise.

\section{Significance of the Study}

More than two thirds of mothers of young children are currently not physically active enough to reap the myriad of physical and mental benefits associated with regular exercise 
(Brown et al., 2001; Garber et al., 2011). However, a mother's demanding and often stressful life presents an ideal situation for which exercise would be extremely advantageous (Verhoef et al., 1992). Many mothers are already aware of the many benefits exercise has to offer, both for

herself, as well as her entire family (Hamilton \& White, 2010; Thomsson, 1999). In order to encourage greater physical activity among this population, efforts must be directed at increasing mothers' awareness of their ability to actively navigate through and manage the many barriers they perceive as preventing them from exercising (Brown et al., 2001; Hamilton \& White, 2011; Harrington, et al., 1992; Netz et al., 2008; Thomsson, 1999; Verhoef \& Love, 1994). Hence, exercise interventions to assist women in this process must take into account mothers' perceived barriers to exercise, and then present mothers with practical and realistic suggestions as to how to overcome those perceived barriers. Therefore, the current research study is important as it includes an empirical test of an intervention that addresses solutions to barriers to exercise through a multi-level social support program.

\section{Limitations of the Study}

This investigation was subject to the following limitations:

1. A sample of convenience was used in this study, as participants needed to be a woman with at least one child under the age of five, for whom she was considered the primary caregiver. Women were recruited from an organization to which the researcher had access; therefore, no random assignment to groups was included in this study.

2. The total number of children that a mother had, nor the ages of all of her children, were factored into the analyses, which might have an additional influence on her time and flexibility.

3. This study was limited by its small sample size. 
4. The duration of this study was eight weeks long. A longer time frame would allow for the determination of true exercise adherence to this type of intervention.

5. No guidelines were imposed upon the control group in regards to increasing or decreasing their physical activity levels. Therefore, any personal changes in activity levels among the control participants must be considered when interpreting the results of the study.

6. The researcher was unable to control for any additional outside social support factors that might have been provided to either the control or treatment groups throughout the duration of the study.

7. This study was limited to heterosexual women who were considered the primary caregivers in their home. Additionally, all but one of the participants were married.

8. While the majority of the control participants returned their post-questionnaire survey packets promptly, four controls did not return their packets until approximately seven weeks after the packets were mailed to them. It is not known whether or not these control participants filled out the questionnaire at the appropriate time and just forgot to send them back, or whether the questionnaires were actually filled out several weeks after the appointed time.

\section{Definition of Terms}

Ethic of Care: The ethic of care is the cultural expectation that a mother should consistently put the needs of others before her own (Gilligan, 1982). In essence, this cultural belief holds that the mother is ever-present in the lives of her children. She is theoretically available all day, every day, and is incessantly sacrificing for the well-being of others, even at the expense of her own well-being, which includes her access to leisure.

Exercise and Physical Activity: For the purpose of this study, these two terms will be used interchangeably to describe any form of activity eliciting physical exertion beyond that of normal 
activities of daily living, and that is undertaken for pleasure or personal satisfaction in order to fulfill a specific purpose (Lox, Martin Ginis, \& Petruzzello, 2010).

Mothers of Young Children: For the purpose of this study, mothers of young children will refer to mothers who are the primary caregivers of at least one child who is under the age of five and who reside in a single urban county in Colorado, USA.

Social Support for Exercise: For the purposes of this study, social support will refer to the support a mother receives specifically in regards to her ability to perform physical activity, which is a better predictor of exercise adherence than general support (Oka, King, \& Young, 1995). Specifically, social support for exercise will refer to instrumental support, emotional support, informational support, companionship support, and validation (Lox et al., 2010). In addition, for the purposes of this study, instrumental support was operationally defined as childcare support, in order to more accurately detect the impact of this particular element that has been identified as highly influential in a mother's desire to exercise (Brown et al., 2001; Hamilton \& White, 2010; Verhoef \& Love, 1994; Verhoef et al., 1992). Ward Members: The term ward members refers to those individuals who attend church together at a specific time on Sundays in the same building. A ward is made up of individuals who reside in a specific geographical region. 


\section{Chapter II}

\section{Review of Literature}

\section{Introduction}

It is nearly impossible to debate the positive effects of exercise for women, including benefits to both physical and mental health (Garber et al., 2011), yet close to half of the women in the United States are not active in their leisure time, and almost a quarter of United States (U.S.) women are only sporadically active (US Department of Health and Human Services, 2000). Compared to men (52.1\%), women (42.6\%) in the U.S. are at greater risk of not meeting the physical activity guidelines for aerobic activity (Centers for Disease Control and Prevention, 2014). Specifically, women with children are in greatest danger of insufficient physical activity levels, as it is estimated that over two-thirds of mothers of young children are not sufficiently active to obtain health benefits (Brown et al., 2001). ${ }^{2}$ Moreover, motherhood itself has been noted as a risk factor for irregular physical activity (Brown et al., 2001; Hamilton \& White, 2010; Verhoef \& Love, 1994; Verhoef et al., 1992). Ironically, a mother's demanding and busy life presents one of the most relevant opportunities for which exercise may be extremely advantageous (Verhoef et al., 1992), especially when one considers the abundance of benefits that can result from regular exercise participation.

\section{Benefits of Exercise for Women}

An indisputable amount of scientific evidence supports the notion that regular exercise is associated with a myriad of positive physical and mental health outcomes in all adults, including women (Garber et al., 2011). Unfortunately, it has been estimated that over two-thirds of mothers of young children are not sufficiently active to obtain health benefits (Brown et al., 2001). The

2 There appears to be a void in the literature regarding the exercise habits of male primary caregivers. 
daily life of a mother of a young child is presumably busy from start to finish. Therefore, any effort to promote physical activity among mothers must provide ample rationale for the effort and sacrifice it will take her to accomplish a regular program of exercise. The evidence supporting this rationale is abundant, and the following section provides such evidence.

Physiological benefits of exercise for women. According to the American College of Sports Medicine (ACSM), scientifically-based evidence demonstrates that the benefits of exercise far outweigh the risks for most adults (Garber et al., 2011). The short-term and longterm benefits of regular exercise are evident across all ages in women (Clapp \& Little, 1995). In order to achieve the greatest overall health, it is imperative that adults engage in regular exercise and limit sedentary behavior (Garber et al., 2011). Furthermore, the benefits of both cardiovascular and strength training exercise modalities are not limited to increased strength, muscular hypertrophy, improved body composition, and increased fitness levels (Abe, DeHoyos, Pollock, \& Garzarella, 2000; Ballor \& Keesey, 1991; Brown \& Wilmore, 1974; Garrow \& Summerbell, 1995; Roig et al., 2009; Wenger \& Bell, 1986). For example, regular participation in physical activity has also been associated with reduced risk of all-cause mortality in women (Blair et al., 1996; Bucksch, 2005; Matthews et al., 2007; Rockhill et al., 2001). As observed by Blair et al. (1996), cardiorespiratory fitness seemed to serve as a protective effect in all individuals, even against the influence of mortality related to complications associated with smoking, elevated cholesterol, and elevated blood pressure.

In addition to protection against death, both walking and vigorous exercise have been associated with fewer incidents of coronary heart disease in women (Khaw et al., 2006; Manson et al., 1999; Oguma \& Shinoda-Tagawa, 2004), as well as fewer incidents of stroke (Gillum, Mussolino, \& Ingram, 1996; Vatten, Nilsen, Romundstad, Droyvold, \& Holmen, 2006; Wendel- 
Vos et al., 2004). Similarly, both walking and vigorous activity have been associated with substantial reductions in risk of developing type 2 diabetes in women (Hu et al., 1999). Related studies have also demonstrated an association between resistance training and improvements in insulin resistance in those who already have type 2 diabetes (Brooks et al., 2007; Ibanez et al., 2005). Furthermore, aerobic exercise (Kelley, 1999; Murphy, Nevill, Murtagh, \& Holder, 2007) and even resistance exercise (Kelley \& Kelley, 2000) have been associated with the potential to lower blood pressure. Aerobic exercise in particular has been associated with improved blood cholesterol concentrations (Kodama et al., 2007; Kraus et al., 2002). Finally, physical activity has also been associated with a reduction of the risk of several cancers, with the strongest observational data supporting reduced risk of colon cancer (Mai et al., 2007; Slattery, Edwards, Ma, Friedman, \& Potter, 1997; Zhang et al., 2006), and breast cancer (Lagerros, Hsieh, \& Hsieh, 2004; Monninkhof et al., 2007; Thune, Brenn, Lund, \& Gaard, 1997; Verloop, Rookus, van der Kooy, \& van Leeuwen, 2000). Thus, regular physical activity may serve as both a treatment for and/or a preventive measure against various chronic diseases.

Of particular interest to women, exercise has also been associated with improved bone mass and reduced risk of osteoporosis (Kohrt, Bloomfield, Little, Nelson, \& Yingling, 2004; Wolff, Van Cronenbourg, Kemper, Kostense, \& Twisk, 1999). After the attainment of peak bone mass, which typically occurs by the third decade of life, bone mass decreases by about $0.5 \%$ per year after the age of 40 years (Kohrt et al., 2004). Furthermore, in women, bone loss begins to accelerate at menopause (Kohrt et al., 2004). Beginning bone loss has been termed osteopenia, and typically progresses to osteoporosis, or advanced bone loss, both of which are a common condition among women (Melton, Chrischilles, Cooper, Lane, \& Riggs, 2005). Perhaps the most devastating threat of osteoporosis is the risk of bone fracture, which occurs in more than $30 \%$ of 
women (U.S. Department of Health and Human Services, 2004). Though research findings are somewhat inconsistent, a large number of longitudinal research studies have demonstrated an association between resistance training and increases in bone mineral density (Westcott, 2012). In addition, physical activity, particularly weight bearing exercise, appears to provide a protective effect against hip fracture risk (Joakimsen, Magnus, \& Fonnebo, 1997). In fact, a meta-analysis of bone density research by Wolff et al. (1999) revealed that exercise interventions were found to either prevent or reverse bone loss in both pre- and post-menopausal women. Going and Laudermilk (2009) discovered similar results in a comparable population. Specifically, weight-bearing exercise and resistance training have been recommended for bone health (Kohrt et al., 2004). Moreover, it is crucial that these types of exercises be done throughout the entire lifespan, not only during select decades of life in order to achieve optimal bone health (Going \& Laudermilk, 2009; Wolff et al.,1999).

Finally, in addition to the prevention of a multitude of diseases, the American College of Sports Medicine (ACSM) has implored physicians to actually use exercise as a prescription in treating a wide array of diseases when prudent, through the medium of their "Exercise is Medicine" campaign (ACSM, 2008). Hence, it would appear that the potential benefits of exercise are abundant, as this modality has been associated with both the prevention and treatment of several numerous health disparities. Even better, this "medicine" can be easy to obtain, relatively inexpensive, and is available to virtually anyone who is interested.

Several interventions have been proposed and implemented with mothers of young children, (Cody \& Lee, 1999; Currie \& Develin, 2002; Haruna et al., 2013); however, considerably few have included specific resistance training exercises in their interventions. In one study, the researchers employed what was termed "cardiovascular and strength components" 
(Norman, Sherburn, Osborne, \& Galea, 2010, p.350). Unfortunately, it was not clearly stated what either of those components entailed, besides that these exercises were tailored to each woman by a physical therapist based on her type of birth delivery and her recovery. Similarly, Currie (2004) implemented an exercise routine that included floor and conditioning exercises targeting the leg and abdominal muscles following a low intensity aerobic session. Regrettably, it is hard to discern from these studies the full extent of the strength exercises performed, as some may categorize floor work, toning, or core work as "strength work," or strength training. This type of incomplete strength training is sometimes included at the conclusion of traditional aerobics classes at the expense of upper body and complete lower body musculature resistance training, and thus may not necessarily constitute a total body strength training routine. Resistance exercise is an essential piece of any well-rounded exercise program, and can provide a myriad of physical benefits as mentioned above (Bibeau, Moore, Mitchell, Vargas-Tonsing, \& Bartholomew, 2010; Brooks et al., 2007; Ibanez et al., 2005; Westcott, 2012), not to mention important psychological benefits (described below). Thus far in the literature, programs designed to target mothers of young children have been lacking in this fundamental resistance element of a woman's exercise program.

Psychological benefits of exercise for mothers. When considered alone, the physiological benefits of exercise for women seem reason enough for a woman to engage in a regular program of physical activity. At the same time, it is quite remarkable to acknowledge that the benefits do not stop with those of a physical nature, as numerous additional psychological benefits are available to women, and mothers in particular, as a result of regular physical activity and exercise, as discussed below. 
Many of the psychological benefits of exercise found in the general population are positive outcomes that could also be applied to mothers. For example, physical activity and exercise have been suggested for use in the treatment and prevention of depression and anxiety (Cooney et al., 2013; Martinsen, 2008; Rethorst, Wipfli, \& Landers, 2009; Strohle, 2009). Likewise, when compared with their sedentary counterparts, physically active individuals have also expressed greater feelings of energy and fewer reports of fatigue (Puetz, 2006). Several studies have also demonstrated accompanying feelings of enhanced well-being (Bartholomew, Morrison, \& Ciccolo, 2005; Yau, 2008) and improved quality of life (Conn, Hafdahl, \& Brown, 2009; Gillison, Skevington, Sato, Standage, \& Evangelidou, 2009) with light and moderate intensity exercise. Equally applicable to women, moderate-intensity exercise has also been associated with enhanced cognitive functioning and protection against neurodegenerative diseases (Kramer \& Erickson, 2007; Ruscheweyh et al., 2011; Smith et al., 2010). Importantly, resistance exercise in particular, that incorporates low intensities and long rest periods, has been shown to produce immediate psychological benefits in the form of increased positive affect (Bibeau et al., 2010). Thus, both resistance training and aerobic exercise have the potential to improve psychological states in women, even without engaging in high intensity activities.

In addition, researchers have discovered several benefits of physical activity that can be associated with the unique situations encountered by mothers with young children, such as having a positive impact on postpartum depression (Armstrong \& Edwards, 2003; Curie \& Develin, 2002; Koltyn \& Schultes, 1997; Sampseelle, Seng, Yeo, Killion, \& Oakley, 1999) and postpartum state anxiety (Koltyn \& Schultes, 1997). Additionally, women across a wide span of ages have noted improved body image (Hausenblas \& Fallon, 2006), and self-esteem (Palmer, 1995; Spence, McGannon, \& Poon, 2005) following an exercise program. Also, especially 
pertinent to mothers, some women have observed that exercise offers them a sort of break, or "time-out" to recharge themselves (Currie, 2004). Some parents have stated that exercising regularly actually helps them to be a better parent by improving their parenting skills (Hamilton \& White, 2011), being a positive role model for their children (Palmer \& Leberman, 2009), and lowering their stress levels (Currie, 2004), which could consequently lower their tendencies to act impulsively and irritably toward their children. In essence, engaging in regular exercise is beneficial for both mother and child (McGannon, Curtin, Schinke, \& Schweinbenz, 2012). Hence, specific benefits are available that are exclusively applicable to mothers of young children as a result of engaging in regular physical activity.

From the evidence presented, it appears that the benefits of exercise and physical activity, both physiological and psychological, far outweigh any risks imposed to a woman. Moreover, these benefits are also specifically applicable to mothers of young children. Finally, when examined as a whole, perhaps the most important finding in the literature on exercise and psychological adaptations is that these benefits do not require an individual to work at strenuously high intensities; rather, this extensive list of benefits can be obtained merely with light to moderate levels of activity.

\section{Perceived Barriers to Exercise among Mothers}

Despite the abundance of physical and psychological benefits available to mothers from engaging in regular physical activity, women have been observed to exercise less frequently than men (Nomaguchi \& Bianchi, 2004), and specifically women with children have been observed to be insufficiently active for health benefit (Brown et al., 2001). This lack of participation is not due to a lack of knowledge, as women have expressed that they know regular exercise is important, even essential (Hamilton \& White, 2010; Thomsson, 1999), and most claim they 
would like to be more active (Brown et al., 2001; Currie \& Develin, 2002). In order to effectively encourage mothers with young children to exercise consistently, it is important to identify the barriers that these women perceive as preventing them from committing to a regular program of physical activity. Without knowledge of what seems to be holding mothers back, it is difficult to implement an intervention to specifically help them overcome the obstacles that make exercise feel impossible. Further, an identified barrier does not necessarily equate to a real, insurmountable obstacle to completing physical activity (Netz, et al., 2008).

Common perceived barriers among mothers. Researchers have discovered a variety of reasons why mothers of young children do not exercise regularly. In general, women have indicated more reasons than men for not exercising (Netz et al., 2008). Unsurprisingly, three of the most frequently cited constraints to women's participation in exercise include what could be termed external, or situational constraints, specifically those of time, fatigue, and having too many other responsibilities (e.g., Brown et al., 2001; Hamilton \& White, 2011; Harrington, Dawson, \& Bolla, 1992; Thomsson, 1999; Verhoef \& Love, 1994). Ranked close behind these factors is the issue of finding childcare (Harrington et al., 1992). Further compounding the challenge of finding childcare is the struggle many mothers have expressed in justifying doing so just for their own personal leisure (Harrington et al., 1992). Furthermore, it is pertinent to note that having children in general appears to be a barrier in itself (Verhoef \& Love, 1992). In response to a questionnaire mailed to women who were 20-49 years old and who were not immediately postpartum, Verhoef and Love (1994) observed that, compared to women without children, mothers were less active in terms of intensity, frequency, and duration of exercise. Researchers noted that this finding existed regardless of the number and ages of the women's children. In contrast, a few researchers have observed that mothers were similar to non-mothers 
in time spent exercising, unless the mothers had children under the age of five (Nomaguchi \& Bianchi, 2004). However, Verhoef, et al. (1992) found that the more children a woman had, the less likely she was to exercise, which is consistent with other data (e.g., Brown et al., 2001; Hamilton \& White, 2010). It appears, then, that the ability to obtain adequate childcare is a common need and a critical factor to be addressed among mothers of young children who desire to exercise.

While some researchers have found increased risk of inactivity among mothers with more children, others have noted that even when taking into account the additional roles of marital status and employment status, motherhood itself has been noted as having the strongest negative effect on the amount of a mother's exercise participation (Verhoef \& Love, 1992; Verhoef et al., 1992). This negative effect of motherhood was found to be true, regardless of whether or not the woman was working outside the home (Verhoef \& Love, 1992). Moreover, Vernon, YoungHyman, and Looney (2010) found that when mothers perceived their babies to be moody, or when their babies' personal characteristics created stress for the mother, this maternal stress also served as a hindrance to her ability to engage in moderate physical activity. For this reason, the authors suggested that interventions to increase a mother's physical activity postpartum should address the benefits of exercise on maternal stress, and should not simply focus only on weight loss. Hence, though motherhood might pose a risk factor for potential inactivity, the benefits of exercise among this particular group could surely counteract the maternal stress that make exercise feel less desirable.

Another commonly reported barrier to exercise among mothers is a lack of adequate social support (Brown et al., 2001; Choi, Henshaw, \& Tree, 2005; Verhoef \& Love, 1994). Social support appears to be a vital key in a mother's ability to exercise. More specifically, 
exercise adherence is more likely when the support is specific to exercise, and not simply general social support (Oka, et al., 1995). Because many stay-at-home mothers function daily in an isolated capacity (Brown et al., 1997), exercise programs that provide adequate childcare would most likely prove to be extremely helpful to a mother wishing to exercise. Social support is necessary when a mother needs assistance with child care, but can also serve to be beneficial in other ways, as well. For example, in their investigation of the beliefs that promote physical activity among parents, Hamilton and White (2011) found that when parents were around other active parents of young children, this environment had the potential to promote physical activity. This observation might have been due to the idea that exercising with like others reduced feelings of guilt about being away from their children. In other words, active parents might feel approval from their peers that physical activity is just a normal part of everyday life, and is not about taking time away from childcare responsibilities. Therefore, social support in the form of validation from others may provide the assistance necessary for some to engage in an exercise program.

On the other hand, though social support may provide assistance for mothers in their exercise goals, seeking social support is difficult for many women. Some feel hesitant to do so, for fear of appearing inadequate in their ability to be everything they perceive society expects them to be, which is a "supermum, superwife, supereverything," or a mother who can do it all by herself (Choi et al., 2005, p. 176). Unfortunately, this unrealistic burden carried by many mothers is only compounded by the additional demands posed by gender differences. For instance, in heterosexual partnerships, females contribute about twice the amount of total household labor that males do, even when they work full-time, have a higher salary, and/or have a higher education than their partners (Blair \& Lichter, 1991). As a result, the hesitancy to ask for help 
may serve as an additional compounding barrier to a mother's desire to be active. Moreover, it is important to note that, to date, the relationship between exercise and parenting roles has only been completed in households where a heterosexual relationship exists. In addition, the research conducted thus far on parents and exercise habits appears to include only mothers who are the primary caregivers, and not fathers as primary caregivers; therefore, it is unknown if similar challenges exist for male primary care givers or individuals in same sex relationships. Regardless, in the current literature, it seems that the supportive role of the partner in heterosexual relationships is crucial if the primary caregiver desires to be physically active.

In addition to external perceived barriers, many mothers also perceive the ability to exercise to be diminished by many conflicting internal perceived barriers. For example, some women feel that they are lacking in sufficient willpower to make exercise a habit, due to the fact that it takes so much planning ahead to effectively carry it out (Thomsson, 1999). Others may profess to have no motivation, due to feeling their efforts are worthless because they will never achieve the type of body that is idealized in the media (McGannon \& Spence, 2012). As an example, in their examination of 40 stories within a Midwestern newspaper section devoted to women's health, McGannon and Spence (2012) concluded that the media portrays one basic image of what is healthy and normal for a woman's body. Moreover, when a woman feels her body does not match such a narrow image, she may feel dissatisfied with her appearance. Hence, this dissatisfaction may encourage a woman to dismiss physical activity to avoid certain types of exercise or public fitness facilities where she might feel like her imperfect body is being judged or compared to others. Body dissatisfaction may also even encourage her to give up on exercise altogether when those ideals are not attained. 
Finally, some women might also avoid exercise as a result of their attitude toward its importance in their lives (Downs, 2006). In a study of an ethnically diverse sample of postpartum women, attitudes, or feelings about the importance of exercise, was a stronger predictor of motivation to exercise than were feelings of personal control or feeling pressure from significant others (Downs, 2006). This greater influence of attitude was more prevalent in Caucasian women than in non-Caucasians. Hence, whether or not a woman chooses to engage in exercise postpartum may depend on how much she values exercise, and whether or not it is high on her list of priorities. To this end, the author offers several suggestions for health professionals who desire to increase a mother's positive attitudes toward exercising, including providing knowledge of the countless of benefits of exercise, discovering the variety of options for exercise in her area of living, and exploring ways to widen her social support network (Downs, 2006). Similarly, as previously mentioned, women have indicated more reasons to avoid exercise than men, specifically in regards to feeling non-athletic or lacking necessary recreational skills (Brown et al., 2001; Harrington et al., 1992; Netz et al., 2008; Verhoef \& Love, 1993). Therefore, some women might benefit from exposure and/or education regarding the plentiful types of exercise, many of which require minimal coordination and athleticism. Finally, in addition to her ethnicity and culture, the degree to which postpartum women perceive their ability to exercise to be easy or difficult might also be heavily influenced by her income (Brown et al., 2001; Downs, 2006; Verhoef \& Love, 1994). Theoretically, many women could bypass this income barrier with creativity and education on what constitutes exercise, as there are plentiful ways to be physically active without spending money.

Motherhood and the ethic of care. While it is certainly understandable that a mother would report factors like limited time and energy to be barriers to her ability to exercise, these 
perceived constraints do not differ markedly from those of the general population. For example, according to the Canadian Fitness and Lifestyle Research Institute (1996), two of the most oft cited excuses for not exercising are lack of time and lack of energy. It might be especially prudent to examine more closely those perceived barriers that are specific to mothers. One of the most frequently expressed constraints by mothers of young children revolves around the concept of an ethic of care (for example, Barkin \& Wisner, 2013; Bialeschki, 1994; Brown et al., 2001; Brown, Small, \& Lumley, 1997; Harrington et al., 1992; Kay, 1998; McGannon \& Schinke, 2013; Miller \& Brown, 2005; Thomsson, 1999). Gilligan (1982) originally proposed the ethic of care ideology as a fundamental component of a woman's moral development, which encompasses the cultural expectation that a mother should consistently put the needs of others before her own. In essence, this cultural belief holds that the mother is ever-present in the lives of her children. She is theoretically available all day, every day, and is incessantly sacrificing for the well-being of others, even at the expense of her own well-being; and this includes her access to leisure. Because this ethic of care concept surfaces in some form in almost every discourse on a mother's perceived inability to exercise, it is essential that it be respected and addressed in any effort to promote physical activity among mothers.

Many mothers appear to be imbued with an ethic of care. In her desire to suitably take care of those she loves, she frequently feels the need to be constantly "on duty," which often requires her to put her own needs behind those of others, including her need for leisure (Harrington et al., 1992, p. 217). Though many mothers recognize the importance of taking care of themselves both physically and emotionally, and also acknowledge that doing so will in turn improve their ability to mother effectively, many also still struggle to do so (Barkin \& Wisner, 2013). In their study of over 30 women (almost all of whom were Caucasian) in their first year 
postpartum, Barkin and Wisner (2013) noted a stark contrast between the belief that self-care was of utmost importance for effective mothering, and the concurrent belief that "selflessness is synonymous with motherhood" (p. 1053). These women demonstrated great difficulty in placing a high priority on their own needs in their first postpartum year. As previously mentioned, many mothers have expressed the desire to be more active (Brown et al., 2001; Currie \& Develin, 2002). At the same time, however, many mothers have also expressed a strong desire to be a good mother (Brown et al., 1997). This conflict between balancing a mother's own needs with those of children creates quite the struggle between two very powerful aspirations, and more often than not, the ethic of care prevails, leaving the mother's hopes to take care of herself by the wayside. Part of the problem may stem from how a woman defines what being a "good mother" really means, as will be discussed in a subsequent section.

Interestingly, some women seem to be willing to put their own activity on hold, accepting that while their children are young it is more important for their children to be active than themselves. In effect, some women submissively consent that after this season of childrearing passes, their time for exercise will come. For example, in their study of parental physical activity among a sample of 61 Caucasian males and females, Hamilton and White (2010) noted that while some parents resented that their physical activity had decreased after having kids, others took more of an attitude of acceptance. It seems that in order to avoid feelings of guilt or selfishness, some parents succumbed to the belief that their time for physical activity would come later, and they were okay with that. There seemed to be a powerful desire to keep up the "supermum" complex, wherein the mother does not forfeit any precious time with her children, and strives to do everything herself to keep the home functioning properly (Hamilton \& White, 2010, p. 21). The mothers in Thommson's (1999) study shared the same moratorium sentiments, 
indicating that they were wives and mothers first, and that this period of putting their children's needs above their own health was only temporary. In the true unselfish nature so characteristic of the ethic of care, these mothers were not even bothered by the act of sacrificing their own health, because being a mother was the most important thing to them (Thommson, 1999). Unfortunately, however, many of these women admitted at a later date that even when their children were grown up, the women had still not started a regular program of physical activity because new duties, such as caring for an elderly parent, had replaced those of caring for children. It seems, therefore, that it would be wise for a mother to closely examine her lifestyle and find a way to make physical activity not only a reality, but especially a priority, for there will always be something that one could argue could account for her leisure time.

Mothers also manifest an ethic of care in the assumption that they do not deserve leisure time, or in other words, that they are not entitled to it (Harrington et al., 1992). According to Harrington et al., this faulty assumption may stem from her performing her work in the home, as opposed to working in the more visible, paid work force. Unfortunately, this erroneous belief may be a result of the strong influence of societal gender roles, because even though the mother may be technically working all day in the home, she does not receive a paycheck or worldly recognition for her efforts there. Indeed, as stated by Brown et al., (1997), the work that women do at home with small children remains "a socially hidden form of labour" (p. 194). As noted by Kay (1998), men's full-time employment seems to legitimize their leisure entitlement. Even though more and more mothers have begun to enter the full-time workforce, unfortunately many underlying societal expectations have been shown to continue to place an unequal burden of the household responsibilities on her shoulders, leaving her even less available time for leisure (Blair, 1991; Kay, 1998). For one woman, her ability to satisfy the ethic of care meant that she 
tried to do her workout at work, in order to avoid feeling guilty by taking time away from her family when she got home (McGannon \& Schinke, 2013). Still, for many women in this predicament, coming home is not exactly a relief from working, as she then assumes a "second shift" being on call for her children after work. In order to feel empowered in taking leisure time, Kay (1996) found that a woman often believed she needed to be working full-time in the workforce, even though it could be argued that a mother is already working (overtime) in the home, all day, seven days a week. Hence, though she may feel more justified in her leisure because she is working outside the home, a whole new barrier is created in the form of more time constraints, further hampering her ability to take time for herself.

In Kay's (1998) examination of 11 full-time employed mothers where both mother and father work full-time outside of the home, a hierarchy of demands was revealed in which mothers devoted their highest attention first to their children, then to their work, and finally to leisure if there was any time left. Notably, even though leisure was seen as an actual need, the subordination of this time resulted in leisure often being relinquished. No matter how much women perceived they needed this leisure time, it could never be prioritized above their family or work (Kay, 1998). Other mothers have similarly expressed these conflicting views (Bialeschki, 1994). In fact, for some women, work even became a form of leisure, as it was often their only time away from their children (Kay, 1998). It is important to note that some women were able to overcome the constraints created by the time pressures of their multiple roles, and they did so by making a regular commitment to a specific activity that was usually out of the home, like attending an evening class (Kay, 1998). Kay noted that an equal level of prioritization was required to make a commitment to leisure for women facing such time pressure. 
Though many women have expressed their avoidance of exercise due to a sense of commitment to their others (Bialeschki, 1994; Brown et al., 2001; Hamilton \& White, 2010; Thomsson, 1999), ironically, exercise may be a vital key to enhancing their ability to care for others. In their interviews with 90 women who had children around the age of two, Brown et al. (1997), asked mothers what they thought it meant to be a good mother. Close to the top of the list were characteristics of patience, and being calm and relaxed. It is important to note that these very characteristics have also been found to be a byproduct of participation in physical activity (Currie, 2004; Koltyn \& Schultes, 1997; Spowart et al., 2008; Spowart et al., 2010). However, mothers rarely mentioned that part of being a good mother meant doing things for themselves, even occasionally (Brown et al., 1997). The discord created between these two dichotomous views might be ameliorated in part by educating women on the utility of exercise to actually improve their mothering abilities, in effect helping them to become the type of "good mother" they are striving so diligently to be.

While many women who do not engage in regular exercise do not consider themselves sedentary due to the plethora of physical tasks required daily of a mother (Thomsson, 1999), there are accompanying physical and mental benefits that would be achieved with a structured and regular exercise program. Whether she prefers to take a "time out" away from the children, or be physically active with them, she needs to feel she deserves that time to take care of herself. Even though a mother's life is undeniably demanding, evidence exists that some mothers are still able to exercise on a regular basis (Appleby \& Fisher, 2009; Bialeschki, 1994; Hamilton \& White, 2010; Lewis \& Ridge, 2005; Miller \& Brown, 2005; Spowart et al., 2008; Spowart et al., 2010). Therefore, while a lack of time is the most frequently cited reason for avoiding exercise, this excuse may actually reflect a lack of interest, or nonexistence of a priority, rather than an 
unavoidable barrier (Verhoef \& Love, 1994). In efforts to reach mothers of young children with realistic exercise options, several program variables have been suggested, such as home exercising, flexible class structuring, provision of on-site child care, concurrent programming for their children, and affordable and adequate day care (Verhoef \& Love, 1993). Several additional interventions have also been proposed, as will be described below.

\section{Interventions for Exercising Mothers}

Because motherhood itself has been indicated as a potential barrier to exercise, some authors have suggested that a determined effort should be made in exercise promotion to target women with children (Verhoef \& Love, 1992). Furthermore, a mother's role has been described as low in control and high in demand, resulting in the potential for a chronically high level of stress for the woman (Barnett \& Baruch, 1987). As such, despite a vexing list of seemingly endless obstacles to participation, of all women, this particular group is likely the very population that would benefit greatly from a regular program of exercise (Verhoef et al., 1992). Every woman's situation is unique, and it is impossible to identify one intervention that would work for every individual mother; however, researchers have proposed numerous suggestions, and their suggested interventions could potentially be modified and applied to mothers in varying situations.

In an effort to address the unique demands a mother faces daily, several exercise interventions have been proposed. One of the most popular of these interventions involves walking groups where women bring their children along in strollers (Currie \& Develin, 2002; Develin \& Currie, 2000). Stroller walking has been shown to result in reduction of stress for the mothers, as well as opportunities for socialization (Currie \& Develin, 2002; Develin \& Currie, 2000). Additional benefits found from stroller walking include the low cost, convenient meeting 
times, non-competitiveness, and no requirement for childcare (Currie \& Develin, 2002; Develin \& Currie, 2000). In addition, Armstrong and Edwards (2003) found that by participating in a stroller walking program three days per week, mothers who had been diagnosed as depressed improved their mental well-being and feelings of depression significantly more than similarly depressed controls who did not participate in the walking program. Moreover, mothers who were not suffering from postpartum depression thought that stroller walking would be beneficial for someone who was depressed and they also postulated that this type of exercise would be beneficial for the mental well-being of any mother (Currie \& Develin, 2002). Not all women found the stroller walking ideal, however, and obstacles included factors like having a difficult child in the stroller, or difficulty taking an older child along (Currie \& Develin, 2002). Hence, stroller walking might not always provide an ideal method of exercise for mothers of young children, as the time spent walking is not truly a time out from her mothering responsibilities, and this method also has the potential to be interrupted by a child.

Likewise, in a similar effort to overcome the barrier of childcare, some researchers have attempted to implement programs where mothers could bring their children with them. Haruna et al. (2013) investigated a four-week group exercise program where three-month postpartum mothers could attend with or without their babies. The women in this study were at least 20 years of age, and were recruited from a hospital and public health centers in Japan. Participants met four times per week for 90 minutes, and performed aerobic type exercises on an exercise ball, followed by stretching. Following the four-week program, Haruna and colleagues observed increased health-related quality of life and self-esteem. In a similar study, Norman and researchers (2010) investigated an eight-week "Mother and Baby" group exercise program, including 161 primiparous and multiparous (single or multiple-birth) English-speaking mothers 
who were six to ten weeks postpartum. This program required that the mothers meet once a week, and perform both cardio and strength exercises. The cardio and strength exercises were combined with parenting education. At the end of the eight-week study, Norman and colleagues (2010) found significant improvements in well-being scores and depressive symptoms. Using a slightly different program design, Cramp and Brawley (2006) investigated an exercise program that was combined with a group-mediated cognitive behavioral intervention, as opposed to just exercise alone. Women in this study had an average age of about 31 years, and the majority were married. In this program, the mothers exercised together twice a week for four weeks, at a facility with a certified fitness instructor. It is unclear how long each exercise session lasted. During this phase, inexpensive childcare was provided, or women could bring their babies to the class. For the following four weeks, participants were encouraged to continue the program by doing their own exercises at home. Both exercise programs resulted in improved exercise participation, but the group who received extra counseling saw greater improvement in overall physical activity and barrier efficacy. The authors concluded that the greater results found among the group with extra counseling probably benefitted from the encouragement to maintain the positive self-regulatory behavioral skills they had received during training. Improved mental well-being and exercise self-efficacy appear to be potential positive outcomes of group exercise classes that invite both early postpartum mothers and their babies to attend.

Exercise interventions for postpartum mothers that did not include bringing the baby to the class have been tested. For example, in a study by Currie (2004), 28 mothers participated in a free 12-week, two days per week, group exercise class with childcare provided on site. Just over half of this group worked full-time at home, and 13 stated that they were involved in some sort of outside employment. Almost all of the mothers in the sample were married. Out of 30 mothers 
in the study, only three reported feeling more stressed as a result of their participation, as opposed to the rest of the women who stated they felt immediately less stressed and less worried after their exercise sessions. The reason some mothers felt more stressed was due mostly to worry about their children in the childcare provided, and the planning and pressure involved in simply making it to the class. Hence, an intervention for mothers of young children might do well to provide childcare by individuals who are familiar with the mothers themselves, in order to relieve any additional stress during the exercise session.

Interestingly, almost all of the mothers in the study by Currie (2004) had indicated that the reason they originally joined the class was to improve their body image. Currie found that many felt pressure to look a certain way after having a baby, and hoped that the class would help them achieve their desired size and shape, or at least the size and shape they felt was expected of them. Despite concerns with body image, however, the majority of the women experienced several positive outcomes as a result of their participation in the exercise program, such as feeling more relaxed and in control, feeling less frustrated and worried, experiencing feelings of freedom and time and space for themselves, an enhanced ability to cope with their daily lives, and overall feelings of greater well-being. A final benefit of Currie's (2004) program was that it was non-competitive, and the researcher noted that the women did not seem to be comparing themselves with each other. This type of program may be ideal for women who are intimidated by the contrasting environment perceived in many public fitness facilities. Other mothers have similarly noted desires to exercise in a non-competitive, family-oriented environment, where the mental benefits of exercise are stressed more than the physical, body-shaping benefits (Lewis \& Ridge, 2005). Likewise, as argued by Currie (2004), women need to emphasize the strengthening, stress-relieving, and enjoyable aspects of exercise rather than simply a limited 
focus on body image, in order to fully gain all the self-nurturing and refreshing benefits physical activity can provide. Clearly, health professionals would do well to emphasize the improved mental and social well-being benefits of exercise as opposed to simply emphasizing weight control, when promoting physical activity among mothers of young children (Lewis \& Ridge, 2005).

Additional researchers have likewise investigated exercise programs that did not involve bringing the children to the exercise class. For example, similar to Currie's (2004) study, Cody and Lee (1999) conducted a study in which 32 mothers participated in a 10-week exercise program, where the women met once per week and could leave their children with the childcare provided on-site. The majority of these women were married, their educational levels varied, and most had more than one child. Prior to commencement of the study, these women were found to be in either the contemplation (i.e., not exercising) or preparation (i.e., exercising irregularly) stages of exercise behavior change. At the weekly meetings, the mothers participated in an exercise program that included cardiovascular elements, as well as education on health and exercise, and a discussion of barriers and maintenance strategies. One of the goals of this intervention was to encourage the mothers to get at least two additional days of similar activity outside of the intervention, and then to continue to exercise regularly after the study ended. At the end of the program, the mothers demonstrated significant increases in perceived social support from partners and friends, and 69\% were more active post-program than they were preprogram. Unfortunately, three months following the end of the study only $41 \%$ of the women were still more active than they were at baseline. The authors deduced that mothers of preschoolers might be more reliant on the structure and childcare naturally built into formal exercise programs, and therefore interventions of this nature might assist women who have the 
desire to exercise, but are limited by childcare options and the constraints imposed on their leisure time due to social roles.

In contrast to interventions involving physical activity, some researchers have sought to empower women through educational means alone. For example, Fahrenwald et al. (2004) provided low socioeconomic status, mostly Caucasian women with an interactive behavior change brochure, in addition to four structured, biweekly provider-delivered telephone calls. By the end of the study, the women who received this treatment had increased their physical activity levels significantly more than controls who did not receive the same education and counseling. Specifically, by the end of the study, the experimental group was performing an average of approximately 155 minutes of moderately intense physical activity (like walking) per week, in contrast to the control group who was performing an average of approximately 75 minutes per week. It is important to note that those women who increased their physical activity levels had indicated that they wanted to make a change at the beginning of the study. Similarly, Miller, Trost, and Brown (2002) observed significantly increased physical activity in mothers who received both a print intervention and a community intervention, compared to women who received just print information, or no intervention. Unfortunately, these positive results did not last for long after the eight-week intervention. The authors concluded that increases in physical activity were likely enhanced by extra partner support and increased self-efficacy. In contrast, Taveras et al. (2011) found no impact on mothers' physical activity levels at six months postpartum, following a program of brief focused conversations with their pediatricians, motivational counseling by a health educator, and group parenting workshops. Clearly, in order for any proposed exercise program to be successful, it appears essential that the program take into consideration the specific needs of each population (White, Randsdell, Vener, \& Flohr, 
2005); this is particularly true for a population as unique and varied as mothers of young children (Scharff et al., 1999).

\section{Practical Strategies of Regular Exercising Mothers}

Though the complex life of a mother presents a vast array of obstacles to her ability to exercise regularly, several mothers have demonstrated that it might be better to instead view those obstacles as hurdles. That is, those challenges might take extra effort to overcome, but they are certainly not unattainable. What do busy mothers do to make consistent physical activity a reality?

Researchers have noted additional strategies that have proven helpful for a mother of young children who desires to be physical active. For example, Cody and Lee (1999) found that effective maintenance strategies used by mothers during a 10-week group exercise program included setting aside regular times for exercise, thinking about how good it feels after exercise, and thinking about the health benefits of exercise. Other researchers have also noted that women who were successfully maintaining an exercise routine needed only to remind themselves of the countless mental and emotional benefits that exercise provided abundantly for them, such as immediate elevations in mood, less tension which resulted in new calmer energy, emotional balance, mental clarity, and a more positive outlook on life (Dacey, Baltzell, \& Zaichkowsky, 2003; Lewis \& Ridge, 2005). For some exercise maintainers, exercise had become part of their identity, and the intrinsic benefits far outweighed external benefits, like weight loss (Dacey et al., 2003). Similarly, Cody and Lee (1999) found that at three months after their structured 10-week group exercise program, in order to maintain adherence, mothers began to focus on personal benefits that made it worth the effort to exercise. Those personal benefits included having more energy, feeling well, losing weight, maintaining fitness, being fit for pregnancy and childbirth, 
having fun, having an opportunity to relax, feeling more capable of coping with their kids, having time away from their kids, and enjoying socializing with other mothers. Indeed, those who exercise more frequently have been observed to do so for more intrinsic reasons, while those who exercise less frequently have more extrinsic reasons for exercising (Thomsson, 1999).

Additional effective strategies for exercise promotion have been observed as well, including giving women choices in the types of exercise they perform, and making physical activity enjoyable, inexpensive, and convenient (White et al., 20005). Also, Brown et al., (2001), discovered that some women would exercise while her family was still asleep, or she would negotiate with her partner to "mind the kids" or share domestic responsibilities so that she could get away to exercise (p. 138). The ability to negotiate and cooperate with her partner seems to be essential in a mother's potential to exercise (Lewis \& Ridge, 2005). Support from friends and family can also be extremely helpful, as noted by Brown et al. (2001), where one group of moms would take turns, rotating one mother at a time watching the children while the others went to play tennis. Finally, after participating in a discussion group, some women discovered that there were in fact excellent childcare facilities nearby that they were not even aware of (Brown et al., 2001). Simple awareness of facilities and childcare options could prove to be a simple solution for some mothers desiring to exercise.

Negotiating constraints. While intuitively it makes sense to assume that the more constraints to physical activity one has, the less time one can spend being active, this is quite the opposite of what Shaw, Bonen, and McCabe (1991) found in their examination of active leisure and constraints among Canadian individuals. The participants in this study reported barriers to their wanting to do more leisure activities, and yet, individuals still participated in their desired activities. Even the most frequently reported constraints (i.e., no time, no facilities nearby) had a 
positive relationship with participation, rather than a negative relationship. Results of this study suggest that just because individuals identify barriers to physical activity, it does not necessarily mean they cannot participate as much as they would like; in fact, they may even be able to participate more. Furthermore, even if those constraints are removed, increased participation is not necessarily the immediate result (Shaw et al., 1991). Such results were found in England, where, even though participants listed money and time as constraints to their leisure, this did not mean that they did not participate (Kay \& Jackson, 1991). Granted, while some participants did not get as much leisure as they wanted, rarely did any refrain completely from participating (Kay \& Jackson, 1991). It is highly unlikely that an individual will confront absolutely zero barriers to engaging in their desired leisure activity. As demonstrated by participants in this study, however, though some extra effort might be required to overcome perceived constraints to leisure, once that leisure activity becomes a priority, it is rarely truly impossible to attain.

Because it has been demonstrated that constraints to leisure do not automatically result in nonparticipation, Jackson, Crawford, and Godby (1993) have suggested an alternative view, that in order to participate in leisure one does not need to remove all constraints, but instead needs to learn to negotiate through them. Henderson and Bialeschki (1993) found agreeable results in their study of women's reactions to their perceived constraints to physical recreation. Over half of the women in this study were either single or separated, and the rest were married. Also, over half of these women had no children. The majority of participants in this study were of European-American descent. Henderson and Bialeschki’s (1993) findings resulted in several themed categories that can help to illustrate how some women confront leisure constraints. On one end of the spectrum, the category of "achievers" took a proactive approach to confronting their barriers, and did not allow those barriers to interfere with their physical activity (p. 395). 
For these women, if she really wanted to do an activity, she would find a way. Achievers were able to negotiate their constraints successfully by stating that their exercise was a priority, even essential, if they were to create a happy family environment. These women made exercise a part of their regular schedules.

In contrast to achievers, "attempters" structured their physical activity around other responsibilities (Henderson \& Bialeschki, 1993, p. 396). Though exercise was not as high on the priority list for them, they were still able to accommodate it most days. "Compromisers" were often married women and/or mothers who tried to combine their leisure activity with family time, while "dabblers" did not make a full commitment to exercise, but instead responded more passively to constraints, disregarding physical activity when they felt they had no control over the situation. Finally, at the opposite end of the spectrum, those in the category "quitters/defaulters" quit participation in physical activity, or never even tried it, even though they were interested in it. This final group expressed numerous constraints, and definitely did not consider physical activity important, nor a priority. Understandably, every woman's needs are highly varied, and no single approach will work in every woman's situation. However, results from Henderson and Bialeschki (1993) demonstrate that perceived barriers to exercise can be overcome when a woman is able to negotiate through her constraints by responding actively to her barriers, rather than passively accepting life as it is handed to her.

Reframing the ethic of care. Just as adhering strictly to the ethic of care is a common practice among mothers desiring to fulfill the role of being a "good mother," so too, is the observation that most mothers who have successfully integrated regular exercise into their daily lives have effectively reframed the ethic of care to include their participation in physical activity (Bialeschki, 1994; Hamilton \& White, 2010; Henderson \& Bialeschki, 1993; Lewis \& Ridge, 
2005; Miller \& Brown, 2005). Truly, the ethic of care directly impacts women's decisionmaking, and it is this framework that guides them in weighing the pros and cons of taking time away from their family to be physically active (Lewis \& Ridge, 2005). Lewis and Ridge (2005) observed that, as opposed to viewing exercise as a source of guilt and shame in taking time away from her family like inactive women, more active women instead reframed exercise as essential to enhancing a mother's ability to take the best care of her family as possible. In their eyes, a happy, healthy mom directly resulted in happy, healthy kids. For another group of parents, deciding whether or not to exercise depended on their beliefs about exercise (Hamilton \& White, 2011). If parents believed that exercise would actually make them a better parent, they were much more likely to exercise. In essence, when a mother engages in active leisure, she can still be described as acting well within the bounds of the ethic of care, because she is not simply doing it selfishly for herself, but in fact she is also doing it for the betterment of others (Bialeshki, 1994; Miller \& Brown, 2005).

Moreover, in addition to improving the mother's mental state and in effect, the mental state of the entire family, many mothers have also expressed their desire to maintain a regular exercise program because they believe that by doing so they are setting an important example for their children to follow (Hamilton \& White, 2010; Lewis \& Ridge, 2005). The adherence to the ethic of care is again revealed here, because by providing an example to their children, mothers are helping them mature into healthy adults themselves. Many parents are well aware of what physical activity is and why it is beneficial (Hamilton \& White, 2010); however, in one study, not all parents made exercise a priority, even though most recognized that it surely needed to be a priority in order to commit to a regular program (Hamilton \& White, 2010). Parents seem to 
recognize the need not to simply avoid exercise because of perceived barriers, but instead to restructure their lifestyles so that exercise does fit into their routines (Hamilton \& White, 2010).

Furthermore, while researchers have noted that motherhood itself is a risk factor for inactivity (Verhoef \& Love, 1992), other researchers have observed a contrasting attitude among mothers who stated that having children actually created increased opportunities for physical activity, as they became more active after having children than before (Lewis \& Ridge, 2005). Thus, rather than viewing motherhood as a barrier to exercise, some women were able to observe it as an enhancement to their otherwise low activity levels. For example, some women were more motivated to exercise because they simply wanted to be able to keep up with their active children, while others found that being physically active with their kids helped them to strengthen their families' relationships (Hamilton \& White, 2010; Lewis \& Ridge, 2005). Still others wanted to be able to live longer so that they could watch their kids grow up (Hamilton \& White, 2010). Importantly, Lewis and Ridge (2005) argued that instead of trying to convince mothers that they "deserve" time to themselves, a better approach might be to reframe the ethic of care by emphasizing the benefits that her physical activity has on her family. Thus, successfully describing a mother's time in physical activity as abundantly beneficial to the wellbeing of her entire family appears to be essential in a mother's ability and desire to exercise regularly. The value of reframing the ethic of care must be taken into consideration by health professionals and others desiring to promote increased physical activity among mothers of young children.

Social support and exercise. Social support models for exercise can be taken from the literature on athlete mothers. At the outset, one might assume that in order to be successful in sport, a mother would need to neglect her child in order to devote sufficient time to train for 
competition. One need not suppose, however, that these elite athlete moms value their sport more than their children. In fact, the opposite appears to hold true for these women who have seemed to construct beliefs about the delicate balance between dedicating time and effort to all the things they hold as high priorities in their lives, including both being a quality parent, and a successful athlete (Appleby \& Fisher, 2009; McGannon et al., 2012; Palmer \& Leberman, 2009; Spowart, Burrows, \& Shaw, 2010). For example, many elite athlete mothers have expressed their inherent devotion to an ethic of care not dissimilar from the devotion expressed by non-athlete mothers (Barkin \& Wisner, 2013; Brown et al., 1997; McGannon \& Schinke, 2013; Miller \& Brown, 2005). In contrast to mothers who have determined the ethic of care to be a barrier to exercise, these mothers have effectively reframed their participation in sport to be an actual enhancing factor in their ability to care for others. In essence, the time and energy expended away from their children is seen as an investment in their efforts to be better mothers.

Because the roles of elite athlete and devoted mother both carry heavy demands, several researchers have sought to determine the strategies these women have discovered that facilitate their continued participation in sport. In one study involving semi-structured interviews with elite athlete mothers from a variety of sports, Palmer and Leberman (2009) observed that a strong passion for sport was the potent motivator for these women to continue to compete after having children. In order to continue participating in something they loved, it was essential for these women to make an extra effort to discover effective strategies to overcome obstacles. For example, these women had learned the necessity of additional planning in order to meet the demands of both their sport and their children. In fact, for some women in this study, this planning appeared to begin long before their babies were even born, as the parents tried to plan the timing of the birth so as not to conflict with the competitive season. The researchers found 
that, while some of these mothers expressed guilt in taking time away from their families, more apparent was their expression of the benefits their involvement in sport had on their children and partners. Such benefits to the mother's family included being a positive role model for her children, increased happiness from participating in sport which helped her to be a better mother overall, allowing her partner to experience part of the nurturing role, and providing her children opportunities to become more independent. Furthermore, according to the authors, these benefits to the family were not limited to the children and partners, but also positively affected the women themselves. For instance, one mother quickly came to understand that the world no longer revolved around herself any longer, and she now had something bigger to live and work for each day. Moreover, Palmer and Leberman concluded that motherhood seemed to develop their resilience and adaptability, hence enhancing their own abilities to confront the rigorous demands that come at elite levels of competition. Interestingly, these women perceived that motherhood actually gave them an added edge as an athlete that other female athletes did not have. It appears that these elite athlete mothers were able to successfully use reframing as a strategy to allow them to overcome feelings of guilt in leaving their children to participate in sport.

Similar observations in attitudes of female athlete mothers have been found in mothers who are elite runners (Appleby \& Fisher, 2009; McGannon et al., 2012), as authors noted that many of these running mothers likewise experienced the initial guilt and feelings of selfishness at the thought of taking time away from their children to train. Over time, however, researchers noted a change in perspective occurred, as mothers began to view motherhood and sport as less contradictory, and instead as more compatible (Appleby \& Fisher, 2009). As an illustration, media narratives of elite marathoner Paula Radcliffe described her as aware of the benefits of 
running for herself, but that this was ultimately permissible only because it was in the best interest of both her and her child, and allowed her to first and foremost be a better mother (McGannon et al., 2012). Likewise, interviews conducted by Appleby and Fisher (2009) revealed that mothers were much happier, less stressed, and felt like better people after they had run. Running, the mothers realized, had become a positive aspect of their identities; it rewarded them with personal satisfaction and incomparable rewards, and therefore should not be discarded from their lives. It is important to note that their new perspective held that motherhood came first, and running was just a nice added bonus on the side. Furthermore, similar to the elite mother athletes interviewed by Palmer and Leberman (2009), some of these elite runners felt that their performance actually increased after giving birth, because now there was less pressure on them to perform at high levels (Appleby \& Fisher, 2009). As an additional result, the intrinsic value of running was brought to the surface for these runners, as they rediscovered their pure love and enjoyment of running itself, as opposed to running purely to compete and win. Paula Radcliffe shared this notion, as she rhythmically chanted her daughter's name in her head as she approached the finish line, which provided the boost in motivation and focus that she needed to pull ahead and win the race (McGannon et al., 2012). Finally, an additional and essential strategy employed by these runners was to rely heavily on the extensive financial and/or emotional support of their partners to devote sufficient time to training and competing.

Several researchers have noted an apparent contradiction between individual pleasure and concern for others in the inherently risky and traditionally hedonistic sports of surfing and snowboarding mothers (Spowart et al., 2010; Spowart, Hughson, \& Shaw, 2008). Both of these sports carry an underlying implication of freedom that starkly contrasts with the more traditional expectation of what a mother should be, that is, selfless, caring, and putting the needs of her 
children before her own (Barkin \& Wisner, 2013; Brown et al., 1997; McGannon \& Schinke, 2013; Miller \& Brown, 2005). Through a series of semi-structured interviews, Spowart et al. (2008) found that non-elite, middle-class snowboarding mothers (ages 31-37, all married to men except one single woman, mixed employment status) of young children had definitely cut back on their time spent on the mountain after having children, and yet they still engaged in their sport for multiple reasons. For one, the mothers could not deny the pure enjoyment they got out of this leisure pursuit. As noted by the authors, in a word, snowboarding was fun. In addition, these mothers expressed a belief that just because they became mothers did not mean that they were no longer entitled to time to themselves. Finally, all women in the study justified their time away from their children in their declaration that snowboarding made them happy and an individual, and because of this, their families directly benefited. As stated by one participant, "It's our kind of mantra: Happy mum is a happy life" (Spowart et al., 2008, p. 194).

One strategy that proved vital to these mothers' ability to snowboard often relied on the support they received from their partners and other family members and friends (Spowart et al., 2008). Some mothers left their children overnight with parents, while others developed a system of trading off childcare with other snowboarding families. That is, one group of parents would go up on the mountain in the morning, and one group would stay with all the children. After meeting for lunch, the groups would swap for the remainder of the day. Indeed, it appeared that these women were willing to go to great lengths to make their leisure pursuit goal a reality, no matter how much additional planning it took. For example, some mothers would wake up extremely early to feed their babies and leave them with a caretaker, get to the mountain early, and then spend the day alternating boarding with pumping their breast milk in the bathroom stalls. In addition, some snowboarding trips took weeks of planning ahead, just to make one 
weekend trip successful. Surely these extra sacrifices were worth all the effort it took to do something that was important to them. As a result, the authors found that these women seemed to feel empowered about their ability to overcome obstacles, and they also seemed to focus more on all the wonderful things about being a mother, as opposed to all of the limitations mothering created. Further, the attitude of "anything's possible," held by these snowboarding moms, created more opportunities for them than constraints (Spowart, et al., 2008, p. 198). Overall, these women were able to leave the confines of home to pursue something they enjoyed, and upon returning, many stated that they could appreciate their roles as wife and mother more, and even looked forward to serving in those roles again once they got home.

In another hedonistic sport study, Spowart et al. (2010) found similar accounts of enjoyment in non-elite surfing mothers. These mothers varied in terms of social status, but all were Caucasian, worked part-time, and were in a long-term heterosexual relationship. Their ages ranged from 28-36 years old. Similar to the methods used in the previous study, Spowart and colleagues (2010) conducted semi-structured interviews with mothers who belonged to a not for profit association of women who would meet at the beach to alternate childcare duties with surfing. As part of this association, one group of women would either watch the children at the beach, or at each other's homes, and then swap with the other group so they could go surfing. Like the snowboarding moms (Spowart, et al., 2008), Spowart and colleagues (2010) noted that these mothers also contended that they had a right to free time away from children, and stated similar assertions of their leisure participation as way to relieve stress and, in effect, make them better equipped to handle (and even enjoy again) the demands of parenting. As an example, for one mother, surfing left her in a better mood and left her feeling like her emotional tank had been filled up, therefore allowing her to give back to her family again (Spowart et al., 2010). 
Coincidentally, a similar mantra was found prevalent among these surfing moms, in essence asserting that when the mother is happy, the whole family is happy. Specifically, one of the stated objectives of the surfing moms group was to "create better family relationships by giving mothers an outlet to enjoy a sport they love," and to enhance efforts to influence children to be more active as well (Spowart et al., 2010, p. 1195). The authors concluded that for the mothers, surfing was not so much simply a fun activity, but was actually a way of living, something that defined who they were. Furthermore, these women believed that by engaging in this type of lifestyle on a regular basis, they were serving as role models for their children in the importance of living an active lifestyle. They were also serving as role models in what it meant to be an individual, which included having hobbies and interests which their children could ideally engage in themselves someday. Indeed, for these surfing mothers, the benefits of regular surfing far outweighed any cons in terms of their own personal satisfaction, as well as the overall wellbeing of their families.

Several common strategies can be drawn as examples from these athlete mothers in overcoming obstacles to exercise. One thing that is particularly noteworthy about these athlete mothers is that they often seemed to focus more on what could be done while still caring for their children, as opposed to focusing so intently on what barriers were limiting them from participating. This often involved extensive planning ahead, and creative maneuvering to make their goals a reality. In addition, for each woman, her sport was a significant part of her identity, and though she wanted to be a mother, even a good mother, she also wanted to maintain that source of who she was as an individual outside of the mother role. Furthermore, in almost every case, the support of partners and other family members was vital for a mother to devote significant amounts of her time and energy to training and/or competition. Interestingly, the 
strategy of "swapping" exercise and childcare duties with other mothers appears, anecdotally, to be an effective strategy to allow mothers to exercise regularly; however, this particular strategy has not yet been empirically examined as a potential effective intervention in the literature. Finally, and perhaps most importantly, all of these athlete mothers were able to reframe the traditional expectations of the ethic of care in such a way that their participation in sport was seen to enhance their family's life, as opposed to distressing it. In other words, their participation in sport contributed to rather than weakened their ability to perform as attentive and compassionate mothers. These mother athletes clearly demonstrate that the roles of mother and athlete can coexist, and a woman should not feel as though she is destined to give up something she loves, including exercise, just because she chooses to have children.

Theoretical framework for exercise intervention. The necessity of social support has been acknowledged in the social ecological model (McLeroy, Bibeau, Steckler, \& Glanz, 1988), which proposes that multiple levels of support, when combined together, can more effectively promote positive health behaviors (see Figure 1). According to this model, though the individual bears responsibility for engaging in a healthy behavior, such as exercise, there are also other levels of support that influence that behavior, including interpersonal relationships with partners, family members, friends, and social networks; organizational influences, such as schools, workplaces, and church groups; community factors, like design, access, and space; and finally, public policy, including the national and territorial levels of laws and policy. An example of the application of this model could be seen in a mother who desires and commits to begin a regular walking program (individual support). To make this goal a reality, she might consider asking her spouse to tend the children while she goes for a walk (interpersonal support). Additionally, she could join a walking group at her local recreation center (organizational support). It would also 
be helpful for her if her environment was conducive to walking, such as providing a variety of walking and hiking trails (community support). Finally, policies enforced in her community, such as prohibition of alcohol and firearms on walking trails, might give her more confidence in her ability to exercise safely (public policy support).

\section{Figure 1}

The social ecological model (McLeroy et al., 1988)

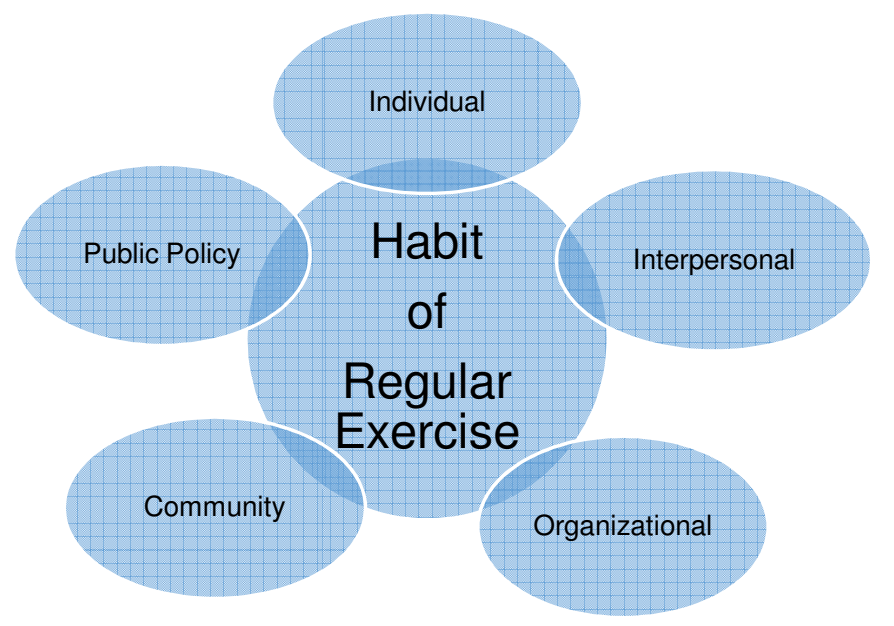

Of all the sources of social support proposed by the social ecological model (McLeroy et al., 1988), perhaps the most pertinent and functional for mothers of young children is interpersonal support, due to the reality that young children cannot be safely left to tend themselves, and daycare costs are often an extra expense some families are not able or willing to pay. Hence, besides her own individual support, it is interpersonal support over which a mother will often have more control. Not to mention, interpersonal support is an essential source of support for those who are primary caregivers of young children (Harrington et al., 1992). Moreover, Wills and Shinar (2000) have suggested that in order to be most effective, social 
support must come in five different forms: instrumental support, emotional support, informational support, companionship support, and validation. Specifically, as they relate to social support for exercise, instrumental support might include tangible practical assistance, like providing childcare during exercise or transportation to exercise facilities. Emotional support might include encouragement or empathy for someone who is exercising. Informational support could include providing guidance on the importance of exercise, and how one should go about being active. Companionship support includes having someone to exercise with. Finally, validation provides an exerciser with the feeling that her experiences, thoughts, and challenges in exercising are normal, and are shared by those around her (Lox et al., 2010). It appears clear that to effectively encourage regular exercise habits among mothers of young children, social support for exercise cannot come solely from one source; rather, it may have to come from several important sources that work together to support this healthy habit.

To reiterate, several researchers have observed that one of the most essential components in encouraging a mother's active lifestyle is social support, and that support must be specific to exercise (Brown et al., 2001; Oka et al., 1995; White et al., 2005). Social support has been found to be especially helpful in the beginning of a new exercise program (White et al., 2005). Furthermore, researchers have also noted that women in particular might enjoy the relational part of exercising with other women (Thomsson, 1999), and being around other mothers who are exercising can increase a woman's self-efficacy by seeing other mothers being active as well (White et al., 2005). To date, no known researchers have empirically investigated the effectiveness of an exercise intervention employing a method of exchanging childcare responsibilities and exercise. Considering the supreme importance of strong social support for exercise, it is clear that this is a crucial area where many proposed exercise interventions for 
mothers of young children have been lacking. Therefore, an exercise intervention for mothers of young children would likely do well to address this apparently essential component by including social support specific to exercise built right into the intervention itself.

\section{Summary}

Mothers of young children are a particular group of women who are not reaping the abundant benefits, both physiological and psychological, that regular exercise can provide (Brown et al., 2001; Garber et al, 2011). Researchers have identified a number of barriers that mothers perceive as preventing them from participating in regular physical activity (Blair \& Lichter, 1991; Harrington et al., 1992; Netz et al., 2008; Nomaguchi \& Bianchi, 2004; Thomsson, 1999; Verhoef \& Love, 1992). Despite those perceived barriers, some mothers have effectively integrated regular physical activity into their daily lives, not allowing anything to get in the way of being active (Cody \& Lee, 1999; Currie \& Develin, 2002; Dacey et al., 2003; Henderson \& Bialeschki, 1993; McGannon \& Schinke, 2013; Shaw et al., 1991). While every mother's situation is different and requires creative negotiation of her unique constraints, one thing remains clear, and that is that mothers need to take an active role in responding to their perceived barriers, rather than passively waiting for larger societal norms to change and create a means for them to do it (Currie, 2004; Verhoef \& Love, 1993). Adequate social support for exercise appears to be essential in a mother's ability to exercise regularly (Brown et al., 2001; Oka et al., 1995; White et al., 2005). Mothers, just like any other group of individuals, could benefit from making the time to exercise, and then valiantly protecting that time (Currie, 2004). Hence, what was once seen as impossible to attain, can instead become a regular and cherished part of a mother's daily life. 


\section{Chapter III}

\section{Methods and Procedures}

\section{Introduction}

The purpose of this study was to determine the effectiveness of a Squat-n-Swap exercise intervention for increasing physical activity levels and perceived social support for exercise among mothers of young children.

\section{Description of Study Population}

A convenience sample of 31 women between the ages of 26 and 41 participated in this study. All women were married to a male partner, except for one woman in the treatment group who was single. Each woman had at least one child under the age of five, and ages of the children ranged from less than one year to 14 years old. The number of children per woman ranged from one child to five children. Any woman who was currently pregnant was restricted from participation in the study. Any woman who became pregnant during the study was required to obtain written permission from her doctor in order to continue participation in the study. Women were deemed healthy and capable of safely engaging in the current study as indicated on the Physical Activity Readiness Questionnaire (PAR-Q; Canadian Society for Exercise Physiology, 2002). Additional subject demographics are provided in Table 1.

\section{Design of the Study}

Comparative analysis was used to evaluate the differences in pre to post-study levels of physical activity and perceived social support for exercise. This study employed a quasiexperimental two group design utilizing samples of convenience. The treatment group participated in the eight-week exercise study described below, and the control group did not participate in the intervention. In addition, open-ended questions served to provide greater insight into the effectiveness of the intervention. 
Table 1

Participant Demographics

Demographics $\quad \mathrm{n}$ (Treatment) $\mathrm{n}$ (Control) $\%$ of Total Participants

\begin{tabular}{|c|c|c|c|}
\hline \multicolumn{4}{|l|}{ Ethnicity (self-identified) } \\
\hline White & 13 & 13 & $83.9 \%$ \\
\hline Black & 2 & 0 & $6.5 \%$ \\
\hline Hispanic & 1 & 2 & $9.7 \%$ \\
\hline \multicolumn{4}{|l|}{ Employment Status } \\
\hline Full-time & 2 & 5 & $22.6 \%$ \\
\hline Part-time & 3 & 6 & $29.0 \%$ \\
\hline Full-time unpaid work in the home & 11 & 4 & $48.4 \%$ \\
\hline \multicolumn{4}{|l|}{ Average Annual Household Income } \\
\hline$<\$ 30,000$ & 4 & 1 & $16.1 \%$ \\
\hline$\$ 30,000-50,000$ & 3 & 3 & $19.4 \%$ \\
\hline$\$ 50,000-75,000$ & 5 & 4 & $29.0 \%$ \\
\hline$\$ 75,000-100,000$ & 3 & 2 & $16.1 \%$ \\
\hline$>\$ 100,000$ & 1 & 5 & $19.4 \%$ \\
\hline \multicolumn{4}{|l|}{ Number of Children } \\
\hline 1 child & 4 & 7 & $35.5 \%$ \\
\hline 2 children & 7 & 6 & $41.9 \%$ \\
\hline 3 children & 3 & 1 & $12.9 \%$ \\
\hline 4 children & 1 & 1 & $6.5 \%$ \\
\hline 5 children & 1 & 0 & $3.2 \%$ \\
\hline
\end{tabular}

\section{Data Collection Procedures}

Instrumentation. Participants' levels of physical activity were measured using a

modified seven-day recall (Appendix A; Sallis et al., 1985). Modified seven-day recall

measurements of physical activity have been found to be valid and reliable indicators of physical activity patterns in various populations (Dishman \& Steinhardt, 2009; Godin \& Shephard, 1985;

Sallis et al., 1985). For the purposes of this study, a modified seven-day recall was adjusted to indicate the number of sessions respondents had engaged in moderate physical activity for at least 30 minutes (the equivalent of one "session"), or vigorous physical activity for at least 20 
minutes (also the equivalent of one "session") in the previous seven days. Moderate physical activity included activities such as walking, yoga, light cycling, and weight training, while vigorous physical activity included activities such as jogging, basketball, and backpacking. Participants indicated how many sessions they completed on every day of the week. For example, if a participant walked for 60 minutes and played basketball for 30 minutes on Monday, together these activities would constitute three sessions.

Perceived levels of social support for exercise were measured using five horizontal middle marked visual analog scales (VAS; see Appendix B; Hartigan, Rainville, Sobel, \& Hipona, 2000; Paul-Dauphin, Guillemin, Virion, \& Briancon, 1999. All scales were 100mm long and accompanied by text describing the extreme limits from not at all to enormous (for childcare support, emotional support, and informational support); not at all to every single time, (for companionship support); and not at all to tremendously (for validation support) in regards to their perceived support for exercise in the five main types of social support proposed by Wills and Shinar (2000). An example of one VAS question (companionship) was, "In the past 8 weeks, please indicate how often you have exercised with any other individuals, such as family members, friends, or activity partners." Participants were instructed to put a mark on the scale according to the degree to which they perceived support for their exercise goals in that area. In addition, participants were also asked to expand on each type of support via a prompt of "please explain," or "please describe." Results were expressed in millimeters from zero (indicating the least amount of support) to 100 (indicating the maximum amount of support). Visual analog scales have been used in various forms in epidemiological and clinical research (Hartigan et al., 2000; Paul-Dauphin et al., 1999), and have been found to be a valid and reliable means of assessing various health parameters, such as pain (Gallagher, Bijur, Latimer, \& Silver, 2002). 
Participants were also asked to assess their perceived change in physical activity over the past eight weeks via the question, "In the last eight weeks, do you think that your physical activity has increased, decreased, or stayed the same? Please explain why."

Finally, in addition to pre-intervention general demographic questions (Appendix C), additional post-intervention open-ended questions were administered to treatment participants in order to measure their perception of the program's effectiveness (Appendix D).

Measurement techniques and procedures. All procedures outlined herein were approved by the Western Washington University Institutional Review Board (IRB), and all participants completed an informed consent prior to engaging in the study (Appendices E and F). This study was partially funded by a grant from the Fund for the Enhancement of Graduate Research at Western Washington University. All participants were recruited from the same local church organization; however, treatment participants and controls were recruited from different meetinghouse locations. In order to obtain a sufficient number of participants, snowball sampling was used in both groups. Participants in both groups were recruited in person during an informational meeting, as well as via email, and were invited to participate as long as they met specific criteria (Appendices $\mathrm{G}$ and $\mathrm{H}$ ). Those recruited for the treatment group who expressed interest in the program via a reply email were given further details regarding the program, including the time and date of the introductory workshop.

If a control participant was deemed eligible to participate in the study, she was then mailed a packet containing the informed consent and questionnaire packet, in addition to a selfaddressed stamped envelope. The survey was sent to her at the beginning of the study, and again eight weeks later. Prompts to remind participants to return the post-questionnaire surveys were given to four participants (who had not responded within four weeks) via email by the 
researcher. To ethically give the control group an opportunity to possibly benefit from the intervention at the end of the study, they were offered the opportunity to participate in a 90minute workshop designed to teach them the exercise training intervention. Unfortunately, there were not enough control participants who indicated interest in this opportunity, so this workshop was not held. However, for those control participants who did express interest in the intervention, contact information from treatment participants was provided (with their permission), so that control participants could join those who were planning to continue employing the Squat-n-Swap model at the conclusion of the study.

Participants in the treatment group met together with the researcher for a 30-minute introductory workshop, where they completed the same survey packet of information as the control group. A detailed description of the contents of the introductory workshop can be found in Appendix I. At this workshop, details of the program logistics were provided, and women were divided into four groups of their choosing, consisting of four to eight women per group. Each group made a specific plan with the researcher as to one day and time they would meet with the researcher the following week. Participants committed to meeting at this day and time for the full duration of the study. If a participant was unable to attend her regularly scheduled workout time, she was encouraged to contact the researcher so the woman could be placed with another group that met on a different day that week. When this occurred, the women of the new group were informed so that the group could plan accordingly for the additional woman and her child(ren).

The following week, the groups met with the researcher at their scheduled times. All workouts were performed in a local church building which was available to use free of charge for the participants (because the lead researcher was also a member of the church). The program 
logistics went as follows. On their predetermined workout day, half of the women met with the researcher in the church gymnasium to perform the exercise routine (described in Appendix J). The other half of the women met together in another large room of the same church building to tend the children. At this time, the women tending the children had an opportunity to socialize with each other while the children played, in essence, engaging in a "play date." After the women in the gymnasium had completed their workout (approximately 40 minutes), the two groups of women would switch places; the mothers tending the children would come into the gymnasium to perform the workout, and the women who had just finished working out would go tend the children.

For the first four weeks, all workouts were performed under the direct supervision of the researcher, who was a certified personal trainer with over seven years of experience in conducting group exercise classes. During the cool down and stretching portion of each workout, the researcher provided instruction in principles of exercise psychology that were pertinent to mothers of young children. Topics included negotiating constraints (Henderson \& Bialeschki, 1993; Shaw et al., 1991), identifying social support sources, prioritizing exercise, the ethic of care, and cognitive reframing (Appendix K). Following this four-week "training" period, participants were each given a handout with pictures and detailed descriptions of the workout they had been doing. In an effort to ascertain exercise adherence, particularly without the influence of a designated leader, the women were encouraged to continue to perform the exercise routine as they had previously done for the next four weeks. Participants were instructed to contact the researcher for assistance via phone calls, texts, and/or emails when there were questions or concerns during these four weeks as to technique, safety, or scheduling,. Although these contacts were not tracked, there were approximately ten occasions when participants 
contacted the researcher, but none of these contacts were in regard to the actual exercise. The majority of contact made regarded scheduling conflicts or switching groups for that week. On the day of the last predetermined workout, the researcher met with each group following the completion of the workout. At this time, the researcher provided closure to the program and readministered the study questionnaire with additional feedback questions (Appendix D).

\section{Data Analysis}

The independent variables were the group (intervention and control), and time (pre and post). The dependent variables were total number of sessions spent in physical activity, as indicated by the modified seven-day recall, and perceived amount of social support for exercise, as indicated on the VAS's. Mean differences in sessions spent in physical activity was analyzed with a mixed between-within groups ANOVA with a significance of $p<0.05$. A chi square analysis was used to analyze whether or not participants perceived that their physical activity had changed over the last eight weeks compared to prior to the intervention. Five additional mixed between-within groups ANOVAs with a significance of $p<0.05$ were used to analyze mean differences in perceived amount of each type of social support pre- and post-intervention. Posthoc t-tests were conducted to determine the source of differences among statistically significant ANOVA interactions utilizing a Bonferroni correction of $p<.0125$. Finally, open-ended answers served to provide additional insight into the quantitative findings of the study. 


\section{Chapter IV}

\section{Results and Discussion}

The purpose of this study was to determine the effectiveness of an eight-week Squat-nSwap exercise intervention for increasing physical activity levels and perceived social support for exercise among mothers of young children. Comparative analysis was used to evaluate the differences in pre to post-study levels of physical activity and perceived social support for exercise. This study employed a quasi-experimental, two group design. The treatment group participated in the eight-week exercise study and the control group did not. Participants' levels of physical activity were measured using a modified seven-day recall (Appendix A; Sallis et al., 1985). In addition, five horizontal middle marked Visual Analog Scales (VAS; Hartigan, et al., 2000; Paul-Dauphin, et al., 1999) were used to measure perceived levels of social support for exercise. Participants were also asked to assess their perceived change in physical activity over the past eight weeks, via the question, "In the last eight weeks, do you think that your physical activity has increased, decreased, or stayed the same? Please explain why." Finally, additional open-ended questions served to provide greater insight into the effectiveness of the intervention.

\section{Results}

Levels of physical activity. The first hypothesis of the current study was that following participation in an eight-week Squat-n-Swap intervention, mothers of young children would have significantly greater levels of physical activity. Means and standard deviations for participants' pre and post physical activity levels can be seen in Table 2. There was no significant interaction effect between treatment and control groups, $F(1,29)=.00, p=.96, \square_{p}^{2}=.000$ for PA over the course of the study. However, the main effect of time for participants' levels of PA was statistically significantly different after the intervention, $F(1,29)=8.47, p=.01, \square_{p}^{2}=.226$. The 
main effect of group for participants' levels of PA was not statistically significantly different, $F$ $(1,29)=1.56, p=.22, \square^{2}=.051$.

Table 2

Means and Standard Deviations for Self-Reported Sessions of Physical Activity in Previous Week

\section{$\underline{\text { Mean (Standard Deviation) }}$}

Treatment Group

Pre

Post

$3.31(2.06)$

Control Group

Pre

Post

A chi square analysis was used to analyze whether or not participants perceived that their physical activity had changed over the last eight weeks compared to prior to the intervention. The minimum expected cell frequency assumption not reached for the chi square so it was not calculated; however, a frequency inspection of the crosstabs analysis still provided valuable information (see Tables 3 and 4). For example, one third of the participants in both the treatment and control groups reported that prior to the study they had increased their physical activity over the previous eight weeks. However, at the end of the study, $86.7 \%$ of the treatment group reported an increase in their PA over the past eight weeks (the duration of the study), compared to only $26.7 \%$ of the control group. In addition, of those treatment participants who had reported decreased levels of PA in the eight weeks preceding the study, 100\% reported an increased level of PA at the end of the study. In contrast, of those control participants who had reported 
decreased levels of PA in the eight weeks preceding the study, $0 \%$ reported increased PA at the end of the study, 50\% reported a decrease in PA, and 50\% reported that their PA had remained the same.

Table 3

Frequencies for Perceived Change in Physical Activity in the Past 8 Weeks-Treatment Group

\begin{tabular}{|c|c|c|c|c|}
\hline & $\frac{\text { Increased }}{\text { (at post) }}$ & $\frac{\text { Decreased }}{\text { (at post) }}$ & $\frac{\text { Stayed the Same }}{\text { (at post) }}$ & $\underline{\text { Total (Pre) }}$ \\
\hline \multicolumn{5}{|l|}{ Increased at Pre } \\
\hline Count ( $\%$ of total) & $4(26.7 \%)$ & $1(6.7 \%)$ & $0(0 \%)$ & $5(31.3 \%)$ \\
\hline \multicolumn{5}{|l|}{ Decreased at Pre } \\
\hline Count ( $\%$ of total) & $6(40 \%)$ & $0(0 \%)$ & $0(0 \%)$ & $6(37.5 \%)$ \\
\hline \multicolumn{5}{|l|}{ Stayed the Same at Pre } \\
\hline Count ( $\%$ of total) & $3(20 \%)$ & $0(0 \%)$ & $1(6.7 \%)$ & $4(25 \%)$ \\
\hline Total & $13(86.7 \%)$ & $1(6.7 \%)$ & $1(6.7 \%)$ & \\
\hline
\end{tabular}


Table 4

Frequencies for Perceived Change in Physical Activity in the Past 8 Weeks-Control Group

\begin{tabular}{|c|c|c|c|c|}
\hline & $\frac{\text { Increased }}{\text { (at post) }}$ & $\frac{\text { Decreased }}{\text { (at post) }}$ & $\frac{\text { Stayed the Same }}{\text { (at post) }}$ & Total (Pre) \\
\hline \multicolumn{5}{|l|}{ Increased at Pre } \\
\hline Count ( $\%$ of total) & $3(20 \%)$ & $1(6.7 \%)$ & $1(6.7 \%)$ & $5(33.3 \%)$ \\
\hline \multicolumn{5}{|l|}{ Decreased at Pre } \\
\hline Count ( $\%$ of total) & $0(0 \%)$ & $1(6.7 \%)$ & $1(6.7 \%)$ & $2(13.3 \%)$ \\
\hline \multicolumn{5}{|l|}{ Stayed the Same at Pre } \\
\hline Count & $1(6.7 \%)$ & $1(6.7 \%)$ & $6(40 \%)$ & $8(53.3 \%)$ \\
\hline Total & $4(26.7 \%)$ & $3(20 \%)$ & $8(53.3 \%)$ & \\
\hline
\end{tabular}

Perceived social support for physical activity. The second hypothesis of the current study was that following participation in an eight-week Squat-n-Swap intervention, mothers of young children would have significantly greater levels of perceived social support for exercise. Means and standard deviations for participants' pre and post perceived levels of support for exercise can be seen in Table 5 and Figure 2. Overall, the second hypothesis of the study was partially supported, as treatment participants reported greater levels of perceived social support for exercise in four of the five measured types of support.

The interaction effect for support in the form of childcare was statistically significantly different, $F(1,29)=16.76, p=.000, \square_{p}^{2}=.366$. Post-hoc paired t-tests revealed a significant difference between pre and post-study levels of perceived childcare support for the treatment group only, $t(15)=-6.79, p=.000, M(S D)_{\text {pre }}=1.66(2.42), M(S D)_{\text {post }}=7.03(2.51), \square^{2}=0.755$, with a very large effect size (Cohen, 1988). 
The interaction effect for support in the form of encouragement was not statistically significant, $F(1,29)=1.43, p=.242, \square_{p}^{2}=.047$. However, the main effect for time was statistically significant, $F(1,29)=4.852, p=.04, \square_{p}^{2}=.143$, resulting in a large effect size (Cohen, 1988), with higher perceived support at posttest (see Table 5). The main effect for group was also statistically significant, $F(1,29)=12.40, p=.001, \square_{p}{ }^{2}=.299$, with a large effect size (Cohen, 1988), with the treatment group reporting greater perceived support than the control group (see Table 5).

The interaction effect for support in the form of information was also statistically significant, $F(1,29)=7.09, p=.013, \square_{p}{ }^{2}=.196$. Post-hoc paired t-tests revealed a difference between pre and post-study levels of informational support for the treatment group, $t=$ $5.82(15), p=.000, M(S D)_{\text {pre }}=2.21(2.29), M(S D)_{\text {post }}=7.24(2.14), \square^{2}=0.693$, with a large effect size found (Cohen, 1988). Post-hoc independent t-tests also revealed a significant difference between the treatment and control group following the study, $t(29)=4.351, p=.000$, $M(S D)_{\text {treatment post }}=7.24(2.14), M(S D)_{\text {control post }}=3.69(2.40), \square^{2}=.395$ and a large effect size (Cohen, 1988).

The interaction effect for support in the form of exercise companionship was also statistically significant, $F(1,29)=15.06, p=.001, \square_{p}{ }^{2}=.342$. Post-hoc paired t-tests revealed a significant difference between pre and post-study levels of companionship support for the treatment group, $t(15)=-6.00, p=.000, M(S D)_{\text {pre }}=1.91(1.75), M(S D)_{\text {post }}=7.12(3.35), \square^{2}=$ .706, with a very large effect size (Cohen, 1988). Post-hoc independent t-tests also revealed a difference between the treatment and control group prior to the study, $t(18.63)=-3.01, p=.007$, $M(S D)_{\text {treatment pre }}=1.91(1.75), M(S D)_{\text {control pre }}=5.38(4.12), \square^{2}=.238$, resulting in a large effect size (Cohen, 1988). 
The interaction effect for support in the form of validation was statistically significant, $F$ $(1,29)=4.85, p=.036, \square_{p}^{2}=.143$. Post-hoc paired t-tests revealed a significant difference between pre and post-study levels of validation support for the treatment group across time, $t(15)=-3.52, p=.003, M(S D)_{\text {pre }}=3.09(3.03), M(S D)_{\text {post }}=6.89(3.00), \square^{2}=.452$, with a large effect size (Cohen, 1998).

Table 5

Means and Standard Deviations for Perceived Social Support for Exercise at Pre and Post Mean (Standard Deviation)

Childcare Encouragement Information With Others Validation

Treatment Group

$\begin{array}{llllll}\text { Pre } & 1.66(2.42) & 5.45(2.95) & 2.21(2.29) & 1.91(1.75) & 3.09(3.03) \\ \text { Post } & 7.03(2.51) & 7.46(2.13) & 7.24(2.14) & 7.12(3.35) & 6.89(3.00)\end{array}$

Control Group

$\begin{array}{llllll}\text { Pre } & 3.51(3.63) & 3.42(2.86) & 2.43(2.89) & 5.38(4.12) & 3.55(2.65) \\ \text { Post } & 4.30(3.50) & 4.02(2.86) & 3.69(2.40) & 4.80(4.14) & 4.22(3.04)\end{array}$

Note . Childcare $=$ support in the form of childcare, Encouragement $=$ support in the form of encouragement Information $=$ support in the form of information, With Others $=$ support in the form of exercising with others, Validation = support in the form of validating others. 
Figure 2

Means for Perceived Social Support for Exercise

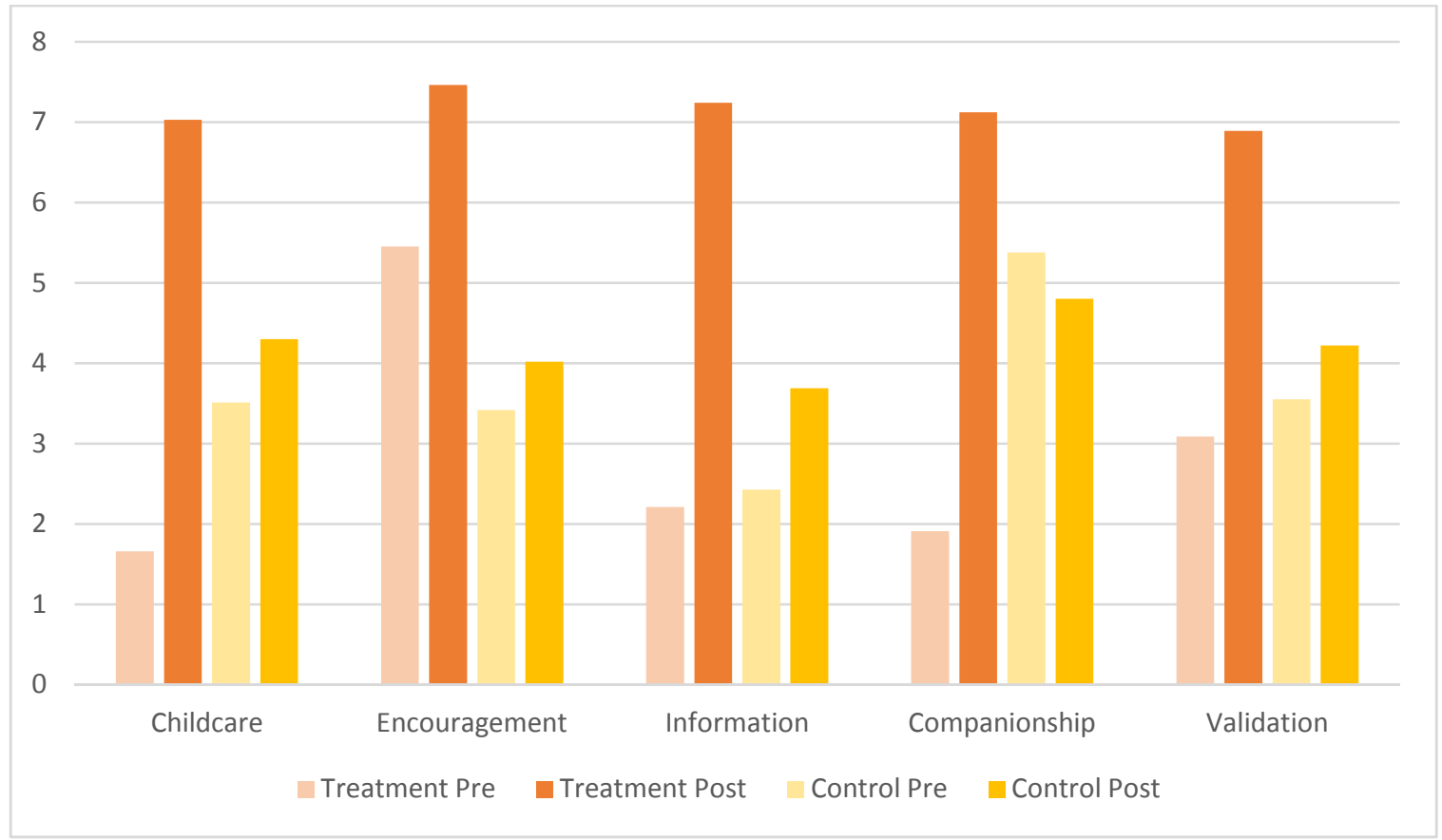

Post-intervention treatment group feedback. Open-ended questions on the postquestionnaire served to provide greater insight into the effectiveness of the intervention for treatment participants. When asked to rate their experience in the Squat-n-Swap program, $81.3 \%$ of the women rated their experience as 5 (very beneficial) and $18.7 \%$ of the women rated their experience as 4 (somewhat beneficial), $M(S D)=4.81(.40)$. In answers to the prompt to rate their participation as either positive or negative, $100 \%$ of participants rated their experience as positive. When asked about the benefits they felt they received, some of the common responses from treatment participants included: "social support," "self-motivation," "self-esteem," "babysitting," "free," "a good habit," "the ability to work out in a small space," and "friendships." In response to the query of how to increase program effectiveness, several women offered the suggestion to shorten the workout portion, as well as to include more structure for the 
childcare aspect in order to keep the children entertained. When asked about their enjoyment of the workouts, $81.3 \%$ of the women stated that they found the workouts to be enjoyable.

\section{Discussion}

Levels of physical activity. One of the purposes of this study was to determine the effectiveness of an eight-week Squat-n-Swap exercise intervention for increasing physical activity levels. Some researchers have observed increased exercise participation following the implementation of a structured exercise program among mothers of young children (e.g., Cramp \& Brawley, 2006). There was an increase in levels of physical activity in participants following the eight-week Squat-n-Swap exercise intervention. Interestingly, however, this increase was found in both the treatment and control groups. Treatment participants' physical activity levels might have increased as a result of the exercise intervention, as indicated in several qualitative responses. For example, as one treatment participant noted about the exercise program, "I have a guaranteed one-day-a-week of physical activity, where before, there was no guarantee I would force myself to do anything." Another treatment participant noted, "Being in this program motivated me to work out throughout the week and to maintain/achieve a higher level of physical activity than what I was previous." Simply joining an exercise group might have encouraged some to become more active outside of the structured workouts, as noted by another treatment participant: "Knowing that someone else is counting on me to get their exercise done helps me get here. Once I'm here, it's easier to be active all week." Similarly, another noted, "Well, I've been committed to working out at least once a week, which was kind of an improvement from my earlier commitment level. I've also thought about fitness a little more, so I've tried to work fitness into my life more." Thus, the increased physical activity levels of treatment participants might be partly explained by their participation in the Squat-n-Swap exercise program. 
On the other hand, the increased activity levels of the control group are not as easily explained. Perhaps the administration of an exercise-related questionnaire served as a prompt for participants to begin exercising more than they were prior to the survey. On the other hand, perhaps participants wanted to portray themselves in a more positive light and faked good on the questionnaire about a healthy habit that many individuals feel they should be doing more often. It is possible that this overestimation of physical activity levels could be given on both the pre- and post-questionnaires. Hence, perhaps the Hawthorne effect might have influenced control participants to overestimate their actual activity levels in order to appear more in line with what is considered good behavior in our health conscious society. On the other hand, the increase in physical activity levels among control participants could also have been a result of timing. This study began at the beginning of a summer, a time when many families may be more active in general due to longer days, warmer weather, and no school for children. Future research in this area should include assessments at different times throughout the year.

It is important to note, however, that the current study assessed physical activity levels in two different ways, and each method provided insight into the exercise behavior of participants. Specifically, on the modified seven-day recall participants were asked to indicate how many sessions of physical activity (moderate for at least 30 minutes, or vigorous for at least 20 minutes) they had engaged in the previous seven days. Participants indicated how many of those sessions they completed on every day of the week. Both treatment and control participants reported a greater number of sessions in the seven days preceding the post survey. In their qualitative responses, some participants in the control group indicated being more active in the previous week prior to the post survey due to uncommon circumstances, such as being on vacation, or having family in town to watch their children. On the other hand, on the second 
question that assessed physical activity, participants were asked to indicate their perceived change in physical activity over the past eight weeks. It appeared from a visual inspection of a crosstabs analysis, that over the past eight weeks, the treatment group perceived a greater increase in their physical activity levels than the control group. This increased perception among treatment participants was found in those who had initially reported decreased physical activity levels before beginning the study, as well as, in those who had reported increased levels prior to the study. It is perhaps particularly noteworthy that of all treatment participants who stated that their physical activity levels had decreased before their participation, all reported that their physical activity levels had increased throughout the duration of the study. Even though treatment participants reported greater perceived physical activity levels over the past eight weeks, future studies would benefit from the inclusion of additional measures of physical activity to more accurately ascertain treatment and control participants' true changes in physical activity. Thus, these results partially support the first hypothesis, in that mothers in both groups increased their physical activity levels when assessed for the previous seven days, and treatment mothers perceived that their physical activity levels had increased overall in the past eight weeks.

Perceived social support for physical activity. Another purpose of the current study was to determine the effectiveness of an eight-week Squat-n-Swap exercise intervention for increasing perceived social support for exercise among mothers of young children. As mentioned previously, one commonly reported barrier to exercise among mothers of young children is a lack of adequate social support (Brown et al., 2001; Choi, et al., 2005; Verhoef \& Love, 1994). Social support appears to be a vital key in a mother's ability to exercise, particularly when the support is specific to exercise, and not simply general social support (Oka, Key, \& Young, 1995). It appears that the Squat-n-Swap intervention produced significant increases in mothers' 
perceptions of social support in regards to their exercise. Of perhaps greatest significance was treatment participants' increase in perceived social support in the form of childcare. The current study purposefully addressed one of the most fundamental perceived obstacles to exercise faced by mothers of young children, that of insufficient childcare (Brown et al., 1997; Verhoef \& Love, 1992). Indeed, several participants' qualitative responses indicated a shared opinion that childcare was their biggest barrier to becoming more physically active. For some women, it was difficult to ask for help, "especially if it is not something urgent or very "important,"” as one participant stated. Similarly, for many women, exercise was not high enough on their priority list to justify seeking help, as mentioned in this comment, "I feel like I cannot ask them to watch my son for exercise as they would see it as something I need to do on my own time not theirs." For other women, feelings of guilt arose when thinking about paying for childcare just to exercise. Another mother wrote, "As a stay at home parent I feel bad at the idea of paying the gym to watch my kid so I can work out." It seems evident then, that this critical need for childcare must be addressed in order for an exercise intervention for mothers of young children to be practical and successful, which is also supported in the literature (Harrington et al., 1992). Treatment participants' levels of perceived support in the form of childcare were significantly greater following the study, and this change was supported by a very large effect size, $\square^{2}=0.755$ (Cohen, 1988). Thus, it appears that one of the primary goals of the exercise program was successful in increasing this type of perceived childcare support, one of the most frequently stated barriers to a mother's ability to be more physically active.

The Squat-n-Swap intervention appeared to result in no statistically significant difference between the treatment and control groups' perceived support in the form of encouragement. Besides simply encouraging someone to be more active, social support for exercise in the form 
of encouragement can also include praise, empathy, caring, and/or concern, and can be a crucial source of support for many in their desire to be more active (Lox et al., 2010). It is not apparent from this study that the women felt that encouragement support levels had changed, which might be an indication of already high preexisting support from significant others, or simply no change in their current levels of this type of support. This conjecture is corroborated by qualitative responses from both the treatment and control groups' descriptions of encouragement support from husbands, sisters, mothers, and friends. Many participants might have perceived significant others as the pre-existing primary source of this type of support, as opposed to fellow participants or the researcher. The current intervention was directed at the woman's behavior that occurred for the most part outside of the view of her significant others, and therefore, this might be one reason why the women perceived no change in this type of support. Had the intervention involved others in the woman's life, this type of support might have played a more relevant role. Therefore, though both the treatment and control groups reported increased levels of this type of support at the end of the study, it is not clear that this increase came as a result of the study.

The exercise intervention did appear to produce a significant increase in treatment participants' perceived support in the form of information related to exercise technique and instruction; and this increase was significantly greater for the treatment group following the study than at the beginning, as demonstrated by a very large effect size, $\square^{2}=0.693$ (Cohen, 1988). Though many women are aware of the benefits of regular exercise (Hamilton \& White, 2010; Thomsson, 1999), there are many who simply lack awareness as to how to exercise to obtain the maximum benefits (Downs, 2006). Hence, one of the advantages of the current study was the information that was provided to treatment participants by a qualified fitness instructor. Qualitative comments revealed that many women were anxious to receive help in this area. As 
one woman indicated, "This is where I am desperate to learn. Trying to do this by myself from looking on the internet is alright but I usually come up with so many un-answered questions or just don't know if I am really doing the right movement and then I always want to give up..." Because there are many health and fitness-related informational resources that are largely unregulated, such as personal blogs and commercial websites, it can be easy for some to be confused by conflicting information found on the internet. The confusion that can often result from such conflicting information might be one reason why learning this type of exercise program in-person, from a qualified professional, might be beneficial. Hence, information from an accessible person on simply how to exercise with young children and instruction on specific exercises to perform might have been an influential component of the Squat-n-Swap exercise program.

Another important finding from this study was that treatment participants indicated a significant increase in their perception of support in the forms of exercise companionship and validating others. The Squat-n-Swap program was designed to provide these two types of support, as mothers who are in very similar life situations had the opportunity to both socialize (a chance for conversational validation) and exercise together (companionship) during the program. Treatment participants reported greater levels of perceived support for companionship following the study compared to their levels beforehand and the effect size for this finding was large (Cohen, 1988); interestingly, however, treatment participants also started the study with significantly lower levels than the control group. Conversely, participants in the control group decreased their levels of companionship support by the end of the study, despite the indication that that their physical activity levels had increased. It appears that the structure of the program was influential on perceptions of companionship support for the treatment group, which was 
supported by both qualitative and quantitative results. For example, one participant noted that, "I don't like to work out alone," and another stated, "It was very hard for me to get motivated to workout alone, but if I know a friend is waiting to meet me, and needs help watching kids, I'm there EVERY time." Interestingly, the latter statement seems also to hint at aspects of the ethic of care (Gilligan, 1982), as this participant appears to be expressing concern not only for her own desire to exercise, but also a desire to meet the needs of someone other than herself. Perhaps, then, the idea of companionship support extends beyond simply meeting a personal desire to exercise with another person, and includes the pressure imposed by the ethic of care to simultaneously put the needs of others above one's own. This may or may not be tolerable pressure as long as the participant is also obtaining the benefits of someone taking care of her. Thus, although the exercise intervention naturally provided treatment participants the opportunity to work out with others (companionship support), it is not entirely clear why this source of support increased for treatment participants and decreased for controls.

Treatment participants also exhibited greater levels of perceived validation from others support by the end of the study. These results are in agreement with Hamilton and White (2011), who found that when parents were around other active parents of young children, it was conducive to the promotion of physical activity. Such validation from others may provide the assistance necessary for some to engage in an exercise program. As previously noted, exercise may be an important time for mothers to socialize with other mothers. Several women echoed these factors in their qualitative responses, including the following participant who stated that, "It has been wonderful to have a group of moms who understand me and face similar trials with kids. It has been nice to talk about problems as we workout too!" Hence, as the current study 
demonstrates, the simple interaction with other women and a chance to socialize might be key ingredients in attracting mothers of young children to such a program.

Overall, although the Squat-N-Swap intervention appears to have been associated with increased perceptions of physical activity levels and social support among treatment participants, results are inconclusive as to whether or not physical activity levels actually increased as a result of the exercise intervention itself. Regardless, it is important to note that positive changes in perceived physical activity levels and perceived social support for exercise were found following only four actual instruction/participant contacts with the treatment group, and that the remaining four weeks were spent without the supervision of the exercise leader (researcher). Such a finding is noteworthy because it accentuates the power of the simplicity of this type of model, and that after very brief contact and assistance from an outside source, the women were still able to carry out the program and maintain consistency on their own. Thus, for mothers of young children, the ability to exercise with a flexible schedule, at a convenient and inexpensive location where childcare is provided, might be crucial elements in her ability to exercise regularly and consistently. 


\section{Chapter V}

\section{Summary, Conclusion, and Recommendations}

\section{Summary}

The purpose of this study was to determine the effectiveness of an eight-week Squat-nSwap exercise intervention for increasing physical activity levels and perceived social support for exercise among mothers of young children who serve as primary caregivers. It was hypothesized that following the study, such mothers of young children would have significantly greater levels of physical activity and perceived social support for exercise. Previous exercise interventions for mothers of young children have yielded mixed results (e.g., Armstrong \& Edwards, 2003; Cody \& Lee, 1999; Currie, 2004; Norman et al., 2010). Therefore, the main purpose of this study was to evaluate the effectiveness of one type of exercise intervention involving alternating physical activity and childcare responsibilities among mothers. This is an intervention that, to the knowledge of the current researcher, has not henceforth been empirically investigated, though anecdotally has proven to be efficacious (Brown et al., 2001; Spowart et al., 2008; Spowart et al., 2010).

\section{Conclusion}

Results from the current study are inconclusive as to the effectiveness of the Squat-NSwap model in increasing levels of physical activity among mothers of young children. This study supports the notion that the Squat-n-Swap intervention was associated with increases in mothers' perceptions of social support related to exercise. Specifically, treatment participants reported greater levels of perceived social support for exercise in the forms of childcare, information, companionship, and validation. Social support for exercise appears to be important in a mother's ability to exercise (Oka, Key, \& Young, 1995). At the post-test, both treatment and control participants reported greater levels of physical activity in the previous week; however, 
only the treatment group reported that their perception of their overall physical activity levels in the past eight weeks had increased.. Overall, because motherhood itself has been noted as a risk factor for irregular physical activity (Brown et al., 2001; Hamilton \& White, 2010; Verhoef \& Love, 1994; Verhoef, Love, \& Rose, 1992), these results could be beneficial to mothers of young children who find it difficult to be physically active due to their demanding schedules and lifestyles.

\section{Recommendations}

A mother's demanding and often stressful life presents an ideal situation for which exercise would be extremely advantageous (Verhoef et al., 1992), and yet it is often this very factor that creates the seemingly impossible task of incorporating one more thing into an alreadypacked schedule. However, results from the current study demonstrate that increases in mothers' social support for exercise and perhaps physical activity levels are possible from participation in a simple exercise program tailored to them. Although a simple model, this model for physical activity will not function adequately unless the participants are committed, specifically because the ability to exercise is dependent upon another person with whom to "swap" exercise and childcare responsibilities. Therefore, it may be crucial for women using this model to choose fellow-exercisers who will likewise be committed to using the model.

Furthermore, one of the fundamental goals of this study was to address the need of childcare support among mothers of young children. Childcare is just one example of instrumental support (Lox et al., 2010) and, future studies would benefit from examining the impact of other types of instrumental support, such as transportation, borrowing equipment, etc. In addition to meeting the need for childcare support, the simple power of in-person information seems to be another key finding of this study. Because information on how to exercise with 
young children seems to be helpful, perhaps simply informing women of this workout option might provide hope for accomplishing their goal to becoming more physically active. Moreover, instruction on specific exercises to perform also appears to assist in increasing physical activity levels in this population.

It is somewhat remarkable to note that positive changes in physical activity and perceived social support for exercise were found following only four actual contacts with the treatment group. Therefore, perhaps only a very small number of sessions of instruction by a qualified fitness instructor could be useful in initiating an exercise program among members of this population. For instance, such instruction could be provided by a certified personal trainer in a commercial fitness setting or even at home.

In addition, another practical consideration of this model is the importance of choosing an activity that is actually enjoyable to participants. For example, at the end of this study, some women in the treatment group informed the researcher that they planned to continue working out together. However, instead of performing circuits of resistance training, they were going to play tennis and do Zumba together. In order to enhance the likelihood of exercise adherence, it is crucial that participants enjoy the activity of choice. Indeed, the possibilities for physical activities seem endless, as even snowboarding and surfing have been successful components of this type of model involving exchanging exercise and childcare responsibilities (Spowart et al., $2008 ; 2010)$.

Future researchers in this area would do well to include a larger sample size of mothers of young children and to randomly assign groups. In addition, it would be interesting to observe the outcome of such an intervention in other types of facilities, such as a commercial fitness center, a community-based childcare center, or even through the use of an online avenue, such as a social 
network site. In any exercise regimen, the likelihood of consistent exercise adherence increases when the individual feels she has autonomy in the choice of what activity to engage in (Ryan \& Deci, 2000). Therefore, future researchers would also benefit from investigating the impact of this exercise model by implementing alternate activities, especially activities that are chosen by the participants themselves, as opposed to the researcher.

Furthermore, because the current study did not include data beyond the duration of the exercise program, it is unknown as to how well participants continued to follow the exercise routine once the study ended. Thus, an equally critical variable to consider in future research is the duration of the program itself, especially the amount of time participants are exercising without the assistance of the researcher. In the current study, participants met with the researcher for a total of four workouts over four weeks, and then exercised in their small groups without a leader for four additional days over the next four weeks, for a total of eight weeks. Therefore, in order to ascertain the true practicality and feasibleness of this type of exercise program, it would be extremely valuable for future studies to extend the length of time for the study, or to perform a follow-up with participants at various intervals following the initial implementation of the program. In order to make long-term tracking of physical activity more manageable, activity levels could be monitored by electronic devices, such as pedometers or movement tracking devices to assess changes in physical activity more specifically. Moreover, these workouts occurred during the summer months, when many families have more flexible schedules. For this reason, future studies would also benefit from being held during other times of the year, especially when older children are in school, since the majority of a child's year is spent in that context. Truly, one of the ultimate desirable outcomes of a study like this would be the continuation of consistent and regular exercise participation by those who initially started the 
program, which is why observing the long-term exercise behaviors of participants would be so helpful.

In conclusion, in order to encourage greater physical activity among caregivers of young children, efforts must be directed at increasing parents' awareness of their ability to actively navigate through and manage the many barriers they perceive as preventing them from exercising. One way to help parents do this is by increasing their access to a variety of social support options. Hence, exercise interventions to assist caregivers in this process must take into account parents' perceived barriers to exercise, and then present them with practical and realistic suggestions as to how to overcome those perceived barriers that can be offered by others in similar situations. Ironically, perhaps the most powerful component of the current study is found in its simplicity. In the Squat-N-Swap model, mothers met just one time per week in a facility that required no cost to participants. The equipment required for the program was very minimal, but the workout could also be easily adapted to a home workout using materials found around the home. Finally, participants met with an actual fitness professional on only four total occasions. Hence, perhaps most significant is this program's potential to be realistic for a wide variety of caregivers, as the equipment and space needed could be minimal and inexpensive (depending on their choice of physical activity). Another aspect of the program that makes it very feasible is that one of the main obstacles to exercise for caregivers, namely, trustworthy and affordable childcare, is provided within the structure of the program. Caregivers of young children face numerous obstacles to physical activity that are not necessarily encountered by those of other circumstances, and, as demonstrated in the current study, when those specific obstacles are addressed in an exercise intervention, the ability to exercise can become a reality for those who desire it. 


\section{References}

Abe, T., DeHoyos, D. V., Pollock, M. L., \& Garzarella, L. (2000). Time course for strength and muscle thickness changes following upper and lower body resistance training in men and women. European Journal of Applied Physiology, 81(3), 174-180.

American College of Sports Medicine, Exercise is Medicine. (2008). Exercise is Medicine: Your Prescription for Health. Retrieved from http://exerciseismedicine.org/

Appleby, K. M., \& Fisher, L. A. (2009). "Running in and out of motherhood”: Elite distance runners' experiences of returning to competition after pregnancy. Women in Sport and Physical Activity Journal, 18(1), 3-17.

Armstrong, K., \& Edwards, H. (2003). The effects of exercise and social support on mothers reporting depressive symptoms: A pilot randomized controlled trial. International Journal of Mental Health Nursing, 12, 130-138.

Ballor, D. L., \& Keesey, R. E. (1991). A meta-analysis of the factors affecting exercise-induced changes in body mass, fat mass and fat-free mass in males and females. International Journal of Obesity, 15(11), 717-726.

Barkin, J. L., \& Wisner, K. L. (2013). The role of maternal self-care in new motherhood. Midwifery, 29, 1050-1055.

Barnett, R. C., \& Baruch, G. K. (1987). Gender and stress. New York: The Free Press.

Bartholomew, J., B., Morrison, D., \& Ciccolo, J. T. (2005). Effects of acute exercise on mood and well-being in patients with major depressive disorder. Medicine and Science in Sports and Exercise, 37(12), 2032-2037. doi: 10.1249/01.mss.0000178101.78322.dd

Bialeschki, M. D. (1994). Re-entering leisure: Transition within the role of motherhood. Journal of Leisure Research, 26(1), 57-74. 
Bialeschki, M. D., \& Michener, S. (1994). Re-entering leisure: Transition within the role of motherhood. Journal of Leisure Research, 260(1), 57-74.

Bibeau, W. S., Moore, J. B., Mitchell, N. G., Vargas-Tonsing, T., \& Bartholomew, J. B. (2010). Effects of acute resistance training of different intensities and rest periods on anxiety and affect. Journal of Strength and Conditioning Research, 24(8), 2184-2191.doi: 10.1519/JSC.0b013e3181ae794b

Blair, S. N., Kampert, J. B., Kohl, H. W., Barlow, C. E., Macera, C. A., Paffenbarger, R. S., \& Gibbons, L. W. (1996). Influences of cardiorespiratory fitness and other precursors on cardiovascular disease and all-cause mortality in men and women. Journal of the American Medical Association, 276(3), 205-210. doi:

10.1001/jama.1996.03540030039029

Blair, S. L., \& Lichter, D. T. (1991). Measuring the division of household labor. Journal of Family Issues, 12(1), 91-113.

Brooks, N., Layne, J. E., Gordon, P. L., Roubenoff, R., Nelson, M. E., \& Castaneda-Sceppa, C. (2007). Strength training improves muscle quality and insulin sensitivity in Hispanic older adults with type 2 diabetes. International Journal of Medical Sciences, 4(1), 19-27.

Brown, P. R., Brown, W. J, Miller, Y. D., \& Hansen, V. (2001). Perceived constraints and social support for active leisure among mothers with young children. Leisure Sciences, 23(3), 131-144. doi: 10.1080/014904001316896837

Brown, C. H., \& Wilmore, J. H. (1974). The effects of maximal resistance training on the strength and body composition of women athletes. Medicine and Science in Sports, 6(3), 174-177. 
Brown, S., Small, R., \& Lumley, J. (1997). Being a 'good mother.' Journal of Reproductive and Infant Psychology, 15, 185-200.

Bucksch, J. (2005). Physical activity of moderate intensity in leisure time and the risk of all cause mortality. British Journal of Sports Medicine, 39(9), 632-638. doi: 10.1136/bjsm.2004.015768

Canadian Fitness and Lifestyle Research Institute. (1996). Progress in prevention. Ottawa: Partners for Physical Activity.

Canadian Society for Exercise Physiology. (2002). PAR-Qforms. Retrieved from http://www.csep.ca/english/view.asp?x=698

Centers for Disease Control and Prevention. (2014). Physical activity. Retrieved from http://www.cdc.gov/physicalactivity/data/facts.html

Choi, P., Henshaw, C., \& Tree, S. B. (2005). Supermum, superwife, supereverything: Performing femininity in the transition to motherhood. Journal of Reproductive and Infant Psychology, 23(2), 167-180. doi: 10.1080/02646830500129487

Clapp, J. F., \& Little, K. D. (1995). The interaction between regular exercise and selected aspects of women's health. American Journal of Obstetrics and Gynecology, 173(1), 2-9.

Cody, R., \& Lee, C. (1999). Development and evaluation of a pilot program to promote exercise among mothers of preschool children. International Journal of Behavioral Medicine, 6(1), 13-29. doi: 10.1207/s15327558ijbm0601_2

Cohen, J. (1988). Statistical power analysis for the behavioral sciences $\left(2^{\text {nd }}\right.$ ed.). New York, NY: Lawrence Erlbaum. 
Conn, V. S., Hafdahl, A. R., \& Brown, L. M. (2009). Meta-analysis of quality-of-life outcomes from physical activity interventions. Nursing Research, 58(3), 175-183. doi: 10.1097/NNR.0b013e318199b53a

Cooney, G. M., Dwan, K., Greig, C. A., Lawlo,r D. A., Rimer, J., Waugh, F. R., . . Mead, G. E. (2013). Exercise for depression. Cochrane Database of Systematic Reviews, 2013(9), CD004366. doi: 10.1002/14651858.CD004366.pub6

Cramp, A. G., \& Brawley, L. R. (2006). Moms in motion: A group-mediated cognitivebehavioral physical activity intervention. International Journal of Behavioral Nutrition and Physical Activity, 3(1), 23. doi: 10.1186/1479-5868-3-23

Currie, J. (2004). Motherhood, stress and the exercise experience: Freedom or constraint? Leisure Studies, 23(3), 225-242.doi: 10.1080/0261436042000251987

Curie, J. L., \& Develin, E. (2002). Stroll your way to well-being: A survey of the perceived benefits, barriers, community support, and stigma associated with pram walking groups designed for new mothers, Sydney, Australia. Health Care for Women International, 23(8), 882-893. doi: 10.1080/07399330290112380

Dacey, M., Baltzell, A., \& Zaichkowsky, L. (2003). Factors in women's maintenance of vigorous or moderate physical activity. Women in Sport and Physical Activity Journal, 12(1), 8797.

Develin, E. D., \& Currie, J. L. (2000). The Strollers Pramwalking Program: A community intervention aimed at increasing the physical activity level of mothers with young children. Health Promotion Journal of Australia: Official Journal of Australian Association of Health Promotion Professionals, 10(1), 57-59. 
Dishman, R. K., \& Steinhardt, M. (2009). Reliability and concurrent validity for a 7-day recall of physical activity in college students. Medicine and Science in Sports and Exercise, 20, $14-25$.

Downs, D. S. (2006). Understanding exercise intention in an ethnically diverse sample of postpartum women. Journal of Sport and Exercise Psychology, 28, 159-170.

Fahrenwald, N. L., Atwood, J. R., Walker, S. N., Johnson, D. R., \& Berg, K. (2004). A randomized pilot test of "Moms on the Move": A physical activity intervention for WIC mothers. Annals of Behavioral Medicine, 27(2), 82-90.

Gallagher, E. J., Bijur, P. E., Latimer, C., \& Silver, W. (2002). Reliability and validity of a visual analog scale for acute abdominal pain in the ED. The American Journal of Emergency Medicine, 20(4), 287-290.

Garber, C. E., Blissmer, B., Deschenes, M. R., Franklin, B. A., Lamonte, M. J., Lee, I., Nieman, D. C., \& Swain, D. P. (2011). Quantity and quality of exercise for developing and maintaining cardiorespiratory, musculoskeletal, and neuromotor fitness in apparently healthy adults: Guidance for prescribing exercise. Medicine and Science in Sports and Exercise, 43(7), 1334-1359. doi: 10.1249/MSS.0b013e318213fefb

Garrow, J. S., \& Summerbell, C. D. (1995). Meta-analysis: Effect of exercise, with or without dieting, on the body composition of overweight subjects. European Journal of Clinical Nutrition, 49(1), 1-10.

Gilligan, C. (1982). In a difference voice. Cambridge, MA: Harvard University Press.

Gillison, F. B., Skevington, S. M, Sato, A., Standage, M., \& Evangelidou, S. (2009). The effects of exercise interventions on quality of life in clinical and healthy populations; a metaanalysis. Social Science and Medicine, 68(9), 1700-1710. 
Gillum, R. F., Mussolino, M. E., \& Ingram, D. D. (1996). Physical activity and stroke incidence in women and men. The NHANES I Epidemiologic Follow-up Study. American Journal of Epidemiology, 143(9), 860-869.

Godin, G., \& Shephard, R. J. (1985). A simple method to assess exercise behavior in the community. Canadian Journal of Applied Sport Sciences, 10(3), 141-146.

Going, S., \& Laudermilk, M. (2009). Osteoporosis and strength training. American Journal of Lifestyle Medicine, 3(4), 310-319. doi: 10.1177/1559827609334979

Hamilton, K., \& White, K. M. (2010). Understanding parental physical activity: Meanings, habits, and social role influence. Psychology of Sport and Exercise, 11(4), 275-285.

Hamilton, K., \& White, K. M. (2011). Identifying key belief-based targets for promoting regular physical activity among mothers and fathers with young children. Journal of Science and Medicine in Sport, 14(2), 135-142.

Harrington, M., Dawson, D., \& Bolla, P. (1992). Objective and subjective constraints on women's enjoyment of leisure. Society and Leisure, 15(1), 203-221.

Hartigan, C., Rainville, J., Sobel, J. B., \& Hipona, M. (2000). Long-term exercise adherence after intensive rehabilitation for chronic low back pain. Medicine and Science in Sports and Exercise, 32(3), 551-557. doi: 10.1097/00005768-200003000-00001

Haruna, M., Watanabe, E., Matsuzaki, M., Ota, E., Shiraishi, M., Murayama, R., Yoshida, M., ... Yeo, S. (2013). The effects of an exercise program on health-related quality of life in postpartum mothers: A randomized controlled trial. Health, 5(3), 432-439. doi: 10.4236/health.2013.53058

Hausenblas, H. A., \& Fallon, E. A. (2006). Exercise and body image: A meta-analysis. Psychology and Health, 21(1), 33-47. doi: 10.1080/14768320500105270 
Henderson, K. A., \& Bialeschki, M. D. (1993). Negotiating constraints to women's physical recreation. Society and Leisure, 16(2), 389-412.

Hu, F. B., Sigal, R. J., Rich-Edwards, J. W., Colditz, G. A., Solomon, C. G., Willett, W. C., . . Manson, J. E. (1999). Vigorous physical activity and risk of type 2 diabetes in women: A prospective study. The Journal of the American Medical Association, 282(15), 14331439. doi: 10.1001/jama.282.15.1433

Ibanez, J., Izquierdo, M., Arguelles, I., Forga, L., Larrion, J. L., Garcia-Unciti, M., . . . Gorostiaga, E. M. (2005). Twice-weekly progressive resistance training decreases abdominal fat and improves insulin sensitivity in older men with type 2 diabetes. Diabetes Care, 28(3), 662-667. doi: 10.2337/diacare.28.3.662

Jackson, E. L., Crawford, D. W., \& Godbey, G. (1993). Negotiation of leisure constraints. Leisure Sciences, 15(1), 1-11.

Joakimsen, R. M., Magnus, J. H., \& Fonnebo, V. (1997). Physical activity and predisposition for hip fractures: A review. Osteoporosis International, 7(6), 503-513.

Kay, T. (1996). Women's work and women's worth. Leisure Studies, 15(1), 49-64.

Kay, T. (1998). Having it all or doing it all? The construction of women's lifestyles in timecrunched households. Society and Leisure, 21(2), 435-454.

Kay, T., \& Jackson, G. (1991). Leisure despite constraint: The impact of leisure constraints on leisure participation. Journal of Leisure Research, 23(4), 301-313.

Kelley, G. A. (1999). Aerobic exercise and resting blood pressure among women: A metaanalysis. Preventive Medicine, 28(3), 264-275. 
Kelley, G. A., \& Kelley, K. S. (2000). Progressive resistance exercise and resting blood pressure: A meta-analysis of randomized controlled trials. Hypertension, 35, 838-843. doi: 10.1161/01.HYP.35.3.838

Khaw, K. T., Jakes, R., Bingham, S., Welch, A., Luben, R., Day, N., \& Wareham, N. (2006). Work and leisure time physical activity assessed using a simple, pragmatic, validated questionnaire and incident cardiovascular disease and all-cause mortality in men and women: The European Prospective Investigation into Cancer in Norfolk prospective population study. International Journal of Epidemiology, 35(4), 1034-1043. doi:

10.1093/ije/dy1079

Kodama, S., Tanaka, S., Saito, K., Shu, M., Sone, Y., Onitake, F., . . Sone, H. (2007). Effect of aerobic exercise training on serum levels of high-density lipoprotein cholesterol: A metaanalysis. Archives of Internal Medicine, 167(10), 999-1008. doi:

10.1001/archinte.167.10.999

Kohrt, W. M., Bloomfield, S. A., Little, K. D., Nelson, M. E., \& Yingling, V. R. (2004). Position stand: Physical activity and bone health. Medicine and Science in Sports and Exercise, 36(11), 1985-1996.

Koltyn, K. F., \& Schultes, S. S. (1997). Psychological effects of an aerobic exercise session and a rest session following pregnancy. Journal of Sports Medicine and Physical Fitness, $37(4), 287-291$.

Kramer, A. F., \& Erickson, K. I., (2007). Capitalizing on cortical plasticity: Influence of physical activity on cognition and brain function. Trends in Cognitive Sciences, 11(8), 342-348.

Kraus, W. E., Houmard, J. A., Duscha, B. D., Knetzger, K. J., Wharton, M. B., McCartney, J. S., ... Slentz, C. A. (2002). Effects of the amount and intensity of exercise on plasma 
lipoproteins. The New England Journal of Medicine, 347, 1483-1492. doi:

10.1056/NEJMoa020194

Lagerros, Y. T., Hsieh, S. F., \& Hsieh, C. C. (2004). Physical activity in adolescence and young adulthood and breast cancer risk: A quantitative review. European Journal of Cancer Prevention, 13(1), 5-12.

Lewis, B., \& Ridge, D. (2005). Mothers reframing physical activity: Family oriented politicism, transgression and contested expertise in Australia. Social Science and Medicine, 60(10), 2295-2306.

Lox, C. L., Martin Ginis, K. A., \& Petruzzello, S. J. (2010). The psychology of exercise: Integrating theory and practice ( $3^{\text {rd }}$ ed.). Scottsdale, AZ: Holcomb Hathaway Publishers, Inc.

Mai, P. L., Sullivan-Halley, J., Ursin, G., Stram, D. O., Deapen, D., Villaluna, D., . . Bernstein, L. (2007). Physical activity and colon cancer risk among women in the California Teachers Study. Cancer Epidemiology, Biomarkers and Prevention, 16(3), 517-525. doi: 10.1158/1055-9965.EPI-06-0747

Manson, J. E., Hu, F. B., Rich-Edward, J. W., Colditz, G. A., Stampfer, M. J., Willett, W. C., Speizer, F. E., . . Hennekens, C. H. (1999). A prospective study of walking as compared with vigorous exercise in the prevention of coronary heart disease in women. The New England Journal of Medicine, 341, 650-658. doi: 10.1056/NEJM199908263410904

Martinsen, E. W. (2008). Physical activity in the prevention and treatment of anxiety and depression [Supplement 47]. Nordic Journal of Psychiatry, 62, 25-29. doi: $10.1080 / 08039480802315640$ 
Matthews, C. E., Jurj, A. L., Shu, X. O., Li, H.L., Yang, G., Li, Q., . . Zheng, W. (2007). Influence of exercise, walking, cycling, and overall nonexercise physical activity on mortality in Chinese women. American Journal of Epidemiology, 165(12), 1343-50. doi: 10.1093/aje/kwm088

McGannon, K. R., Curtin, K., Schinke, R. J., \& Schweinbenz, A. N. (2012). (De)Constructing Paula Radcliffe: Exploring media representations of elite running, pregnancy and motherhood through cultural sport psychology. Psychology of Sport and Exercise, 13, 820-829.

McGannon, K. R., \& Schinke, R. J. (2013). “My first choice is to work out at work; then i don't feel bad about my kids": A discursive psychological analysis of motherhood and physical activity participation. Psychology of Sport and Exercise, 14, 179-188.

McGannon, K. R., \& Spence, J. C. (2012). Exploring news media representations of women’s exercise and subjectivity through critical discourse analysis. Qualitative Research in Sport, Exercise and Health, 4(1), 32-50.

McLeroy, K. R., Bibeau, D., Steckler, A., \& Glanz, K. (1988). An ecological perspective on health promotion programs. Health Education Quarterly, 15, 351-377.

Melton, L. J., Chrischilles, E. A., Cooper, C., Lane, A. W., \& Riggs, B. L. (2005). How many women have osteoporosis? Journal of Bone and Mineral Research, 20(5), 886-892. doi: 10.1359/jbmr.2005.20.5.886

Miller, Y. D., \& Brown, W. J. (2005). Determinants of active leisure for women with young children-An "ethic of care" prevails. Leisure Sciences, 27, 405-420. doi: $10.1080 / 01490400500227308$ 
Miller, Y. D., Trost, S. G., \& Brown, W. J. (2002). Mediators of physical activity behavior change among women with young children. American Journal of Preventive Medicine, 23(2S), 98-103.

Monninkhof, E. M., Elias, S. G., Vlems, F. A., van der Twell, I., Schuit, A. J., Voskuil, D. W., \& van Leeuwen, F. E. (2007). Physical activity and breast cancer: A systematic review. Epidemiology, 18(1), 137-157. doi:10.1097/01.ede.0000251167.75581.98

Murphy, M. H., Nevill, A. M., Murtagh, E. M., \& Holder, R. L. (2007). The effect of walking on fitness, fatness and resting blood pressure: A meta-analysis of randomised, controlled trials. Preventive Medicine, 44(5), 377-385.

Netz, Y., Zeev, A., Arnon, M., \& Tenenbaum, G. (2008). Reasons attributed to omitting exercising: A population-based study. International Journal of Sport and Exercise Psychology, 6(1), 9-23. doi: 10.1080/1612197X.2008.9671851

Nomaguchi, K. M., \& Bianchi, S. M. (2004). Exercise time: Gender differences in the effects of marriage, parenthood, and employment. Journal of Marriage and Family, 66, 413-430.

Norman, E., Sherburn, M., Osborne, R. H., \& Galea, M. P. (2010). An exercise and education program improves well-being of new mothers: A randomized controlled trial. Physical Therapy, 90(3), 348-355.

Oguma, Y., \& Shinoda-Tagawa, T. (2004). Physical activity decreases cardiovascular disease risk in women: Review and meta-analysis. American Journal of Preventive Medicine, $26(5), 407-418$

Oka, R. K., King, A. C., \& Young, D. R. (1995). Sources of social support as predictors of exercise adherence in women and men ages 50 to 65 years. Women's Health: Research on Gender, Behavior, and Policy, 1(2), 161-175. 
Palmer, L. K. (1995) Effects of a walking program on attributional style, depression, and selfesteem in women. Perceptual and Motor Skills, 81, 891-898. doi: 10.2466/pms.1995.81.3.891

Palmer, F. R., \& Leberman, S. I. (2009). Elite athletes as mothers: Managing multiple identities. Sport Management Review, 12(4), 241-254.

Paul-Dauphin, A., Guillemin, F., Virion, J., \& Briancon, S. (1999). Bias and precision in visual analogue scales: A randomized controlled trial. American Journal of Epidemiology, 150(10), 1117-1127.

Puetz, T. W. (2006). Physical activity and feelings of energy and fatigue: Epidemiological evidence. Sports Medicine, 36(9), 767-780. doi: 10.2165/00007256-200636090-00004

Rethorst, C. D., Wipfli, B. M., \& Landers, D. M. (2009). The antidepressive effects of exercise: A meta-analysis of randomized trials. Sports Medicine, 39(6), 491-511.

Rockhill, B., Willett, W.C., Manson, J.E., Leitzmann, M.F., Stampfer, M.J., Hunter, D.J., \& Colditz, G.A. (2001). Physical activity and mortality: A prospective study among women. American Journal of Public Health, 91(4), 578-583.

Roig, M., O’Brien, K., Kirk, G., Murray, R., McKinnon, P., Shadgan, B., . . Reid, W., D. (2009). The effects of eccentric versus concentric resistance training on muscle strength and mass in healthy adults: A systematic review with meta-analysis. British Journal of Sports Medicine, 43, 556-268. doi: 10.1136/bjsm.2008.051417

Ruscheweyh, R., Willemer, C., Kruger, K., Duning, T., Warnecke, T., Sommer, J., . . Floel. (2011). Physical activity and memory functions: An interventional study. Neurobiology of Aging, 32(7), 1304-1319. 
Ryan, R. M., \& Deci, E. L. (2000). Self-determination theory and the facilitation of intrinsic motivation, social development, and well-being. American Psychologist, 55(1), 68-78.

Sallis, J. F., Haskell, P., Wood, P. D., Fortmann S. P., Rogers, T., Blair, S. N., \& Paffenbarger, R. S. (1985). Physical Activity assessment methodology in the five city-project. American Journal of Epidemiology, 121, 91-106.

Sampseelle, C. M., Seng, J., Yeo, S., Killion, C., \& Oakley, D. (1999). Physical activity and postpartum well-being. Journal of Obstetric, Gynecologic, and Neonatal Nursing, 28(1), 41-49. doi: 10.1111/j.1552-6909.1999.tb01963.x

Scharff, D. P., Homan, S., Kreuter, M., \& Brennan, L. (1999). Factors associated with physical activity in women across the life span: Implications for program development. Women and Health, 29(2), 115-134. doi: 10.1300/J013v29n02_08

Shaw, S. M. Bonen, A., \& McCabe, J. F. (1991). Do more constraints mean less leisure? Examining the relationship between constraints and participation. Journal of Leisure Research, 23(4), 286-300.

Slattery, M. L., Edwards, S. L., Ma, K. N., Friedman, G. D., \& Potter, J. D. (1997). Physical activity and colon cancer: A public health perspective. Annals of Epidemiology, 7(2), 137-145.

Smith, P. J., Blumenthal, J. A., Hoffman, B. M., Cooper, H., Strauman, T. A., Welsh-Bohmer, K., ... Sherwood, A. (2010). Aerobic exercise and neurocognitive performance: A metaanalytic review of randomized controlled trials. Psychosomatic Medicine, 72(3), 239-252. doi: 10.1097/PSY.0b013e3181d14633

Spence, J. C., McGannon, K. R., \& Poon, P. (2005). The effect of exercise on global self-esteem: A quantitative review. Journal of Sport and Exercise Psychology, 27(3), 311-334. 
Spowart, L., Burrows, L., \& Shaw, S. (2010). 'I just eat, sleep and dream of surfing': When surfing meets motherhood. Sport in Society, 13, (7-8), 1186-1203. doi: $10.1080 / 17430431003780179$

Spowart, L., Hughson, J., \& Shaw, S. (2008). Snowboarding mums carve out fresh tracks: Resisting traditional motherhood discourse? Annals of Leisure Research, 11, (1-2), 187204. doi: $10.1080 / 11745398.2008 .9686792$

Strohle, A. (2009). Physical activity, exercise, depression and anxiety disorders. Journal of Neural Transmission, 116(6), 777-784. doi: 10.1007/s00702-008-0092-х

Taveras, E. M., Blackburn, K., Gillman, M. W., Haines, J., McDonald, J., Price, S., \& Oken, E. (2011). First steps for mommy and me: A pilot intervention to improve nutrition and physical activity behaviors of postpartum mothers and their infants. Maternal and Child Health Journal, 15, 1217-1227. doi: 10.1007/s10995-010-0696-2

Thomsson, H. (1999). Yes, I used to exercise, but . . -A feminist study of exercise in the life of Swedish women. Journal of Leisure Research, 31(1), 35-56.

Thune, I., Brenn, T., Lund, E., \& Gaard, M. (1997). Physical activity and the risk of breast cancer. New England Journal of Medicine, 336(18), 1269-1275. doi: 10.1056/NEJM199705013361801

United States Department of Health and Human Services. (2000). Healthy people 2010: Understanding and improving health. Government Printing Office.

United States (U.S.) Department of Health and Human Services. (2004). Bone health and osteoporosis: A report of the Surgeon General. U.S. Department of Health and Human Services, Office of the Surgeon General. 
Vatten, L. J., Nilsen, T. I., Romundstad, P. R., Droyvold, W. B., \& Holmen J. (2006). Adiposity and physical activity as predictors of cardiovascular mortality. European Journal of Preventive Cardiology, 13(6), 909-915. doi: 10.1097/01.hjr.0000239463.80390.52

Verhoef, M. J., \& Love, E. J. (1992). Women's exercise participation: The relevance of social roles compared to non-role-related determinants. Canadian Journal of Public Health, 83(5), 367-370.

Verhoef, M. J., \& Love, E. J. (1994). Women and exercise participation: The mixed blessings of motherhood. Health Care for Women International, 15(4), 297-306.

Verhoef, M. J., Love, E. J., \& Rose, M. S. (1992). Women’s social roles and their exercise participation. Women and Health, 19(4), 15-29.

Verloop, J., Rookus, M. A., van der Kooy, K., \& van Leeuwen, F. E. (2000). Physical activity and breast cancer risk in women aged 20-54 years. Journal of the National Cancer Institute, 92(2), 128-135. doi: 10.1093/jnci/92.2.128

Vernon, M. M., Young-Hyman, D., \& Looney, S. W. (2010). Maternal stress, physical activity, and body mass index during new mothers' first year postpartum. Women and Health, 50, 544-562. doi: 10.1080/03630242.2010.516692

Wendel-Vos, G. C., Schuit, A. J., Feskens, E.J., Boshuizen, H. C., Verschuren, W. M., Saris, W.H., \& Kromhout, D. (2004). Physical activity and stroke. A meta-analysis of observational data. The International Journal of Epidemiology, 33(4), 787-798. doi: 10.1093/ije/dyh168

Wenger, H. A., \& Bell, G. J. (1986). The interactions of intensity, frequency and duration of exercise training in altering cardiorespiratory fitness. Sports Medicine, 3(5), 346-356. 
Westcott W. (2012). Resistance training is medicine: Effects of strength training on health. Current Sports Medicine Reports, 11(4), 209-216.

White, J. L., Randsdell, L. B., Vener, J., \& Flohr, J. A. (2005). Factors related to physical activity adherence in women: Review and suggestions for future research. Women and Health, 41(4), 123-148. doi: 10.1300/J013v41n04_07

Wills, T. A., \& Shinar, O. (2000). Measuring perceived and received social support. In S. Cohen, L. G. Underwood, \& B. H. Gottlieb (Eds.), Social support measurement and intervention (pp. 86-135). New York, NY: Oxford University Press.

Wolff, I., Van Cronenbourg, J., Kemper, H. C. G., Kostense, P. J., \& Twisk, J. W. R. (1999). The effect of exercise training programs on bone mass: A meta-analysis of published controlled trials in pre- and postmenopausal women. Osteoporosis International, 9, 1-12.

Yau, M. K. (2008). Tai chi exercise and the improvement of health and well-being in older adults. Medicine and Sport Science, 52, 155-165. doi: 10.1159/000134296Zhang, Y., Cantor, K. P., Dosemeci, M., Lynch, C. F., Zhu, Y., Zheng, T. (2006). Occupational and leisure-time physical activity and risk of colon cancer by subsite. Journal of Occupational and Environmental Medicine, 48(3), 236-243. doi:

10.1097/01.jom.0000199521.72764.26 


\section{Appendix A}

\section{7-day Recall Questionnaire}

\section{7-day Recall of Physical Activity:}

Directions: Please list the number of physical activity sessions you completed in the last week.

1. How many sessions of moderate physical activity did you complete last week (at least $\mathbf{3 0}$ minutes or longer)?

${ }^{*}$ NOTE: Examples of moderate physical activity include walking, yoga, light cycling, weight training, etc.

Example: Last week I did yoga for an hour on Monday. On Saturday, I went for a 30 min walk in the morning, and then I did resistance training for 45 min that evening. I completed $\mathbf{3}$ sessions of moderate physical activity. My chart would look as follows:

\begin{tabular}{|l|l|l|l|l|l|l|}
\hline Sunday & Monday & Tuesday & Wednesday & Thursday & Friday & Saturday \\
\hline & 1 & & & & & 2 \\
\hline
\end{tabular}

YOUR MODERATE PHYSICAL ACTIVITY LAST WEEK:

\begin{tabular}{|l|l|l|l|l|l|l|}
\hline Sunday & Monday & Tuesday & Wednesday & Thursday & Friday & Saturday \\
\hline & & & & & & \\
\hline
\end{tabular}

2. How many sessions of vigorous physical activity did you complete last week (at least $\mathbf{2 0}$ minutes or longer)?

**NOTE: Examples of vigorous physical activity include jogging, basketball, backpacking, etc.

Example: Last week I played basketball for an hour on Tuesday. On Saturday, I went for a 20 min jog in the morning, and then went backpacking for 30 min that afternoon. I completed 3 sessions of vigorous physical activity. My chart would look as follows:

\begin{tabular}{|l|l|l|l|l|l|l|}
\hline Sunday & Monday & Tuesday & Wednesday & Thursday & Friday & Saturday \\
\hline & & 1 & & & & 2 \\
\hline
\end{tabular}

YOUR VIGOROUS PHYSICAL ACTIVITY LAST WEEK:

\begin{tabular}{|l|l|l|l|l|l|l|}
\hline Sunday & Monday & Tuesday & Wednesday & Thursday & Friday & Saturday \\
\hline & & & & & & \\
\hline
\end{tabular}




\section{Appendix B \\ Social Support for Exercise Questionnaire}

The following questions will address the amount and type of social support you have available to you in reaching your exercise goals. Social support can come in many forms, including (but not limited to ) extended and immediate family members, friends, neighbors, fellow church members, coworkers, fellow exercise class members, physicians, and exercise instructors.

Please answer each question as fully and accurately as possible, as it pertains to the LAST

8 WEEKS. Please do not list any names of individuals.

1. In the past 8 weeks, please indicate the amount of support from others that you have received in the form of childcare that has helped you achieve your exercise goals. Indicate by placing an " $\mathrm{X}$ " on the line below.

Please explain your answer:

2. In the past 8 weeks, please indicate the amount of support you have received to achieve your exercise goals in the form of encouragement, empathy, caring, and/or concern. (Examples: praise for your hard work; encouragement from another to work harder; sympathy from someone when you are complaining about sore muscles.) Indicate by placing an " $\mathrm{X}$ " on the line below.

Please explain your answer: 
3. Please indicate the extent of social support you have received in the last 8 weeks in the form of information on how to reach your exercise goals. (Examples: informational support in the form of giving directions, advice, or suggestions about how to exercise; explaining to you why a physical activity is important to improve your health, and what benefits you can expect to receive from participating; receiving feedback regarding your exercise progress.) Indicate by placing an " $\mathrm{X}$ " on the line below.

Please explain your answer:

4. In the past 8 weeks, please indicate how often you have exercised with any other individuals, such as family members, friends, or activity partners. Indicate by placing an "X" on the line below. 
5. In the past 8 weeks, to what extent have you felt supported by individuals in your life who are in a similar life situation, and who are able to relate to the thoughts, feelings, problems, and experiences that you have had regarding your efforts to exercise? Indicate by placing an " $\mathrm{X}$ " on the line below.

Please explain your answer:

6. In the last eight weeks, do you think that your physical activity has increased/decreased/stayed the same? (PLEASE CIRCLE)

Please explain why: 


\section{Appendix C}

\section{Demographics Questions}

Please indicate the following information about yourself:

1. Age:

2. Race/ethnicity/prefer not to respond:

3. Average annual income of household (please circle):

$$
<\$ 30,000 \quad \$ 30,000-50,000 \quad \$ 50,000-75,000 \quad \$ 75,000-100,000 \quad>\$ 100,000
$$

4. How many children do you currently have:

5. What are the ages of your children:

6. Are you currently Married/Single/Widowed (please circle)

7. Are you currently employed? Full-time/Part-time/Full-time unpaid work in the home (please circle)

8. If employed, how many hours per week do you work? 


\section{Appendix D \\ Additional Post-Intervention Qualitative Questions}

\section{Squat-n-Swap Feedback}

1. How was your experience in the Squat-n-Swap program?

$\begin{array}{ccccc}\mathbf{1} & \mathbf{2} & \mathbf{3} & \mathbf{4} & \mathbf{5} \\ \text { Very } & \begin{array}{c}\text { Somewhat } \\ \text { Unhelpful }\end{array} & \text { Neutral } & \begin{array}{c}\text { Somewhat } \\ \text { Beneficial }\end{array} & \begin{array}{c}\text { Very } \\ \text { Beneficial }\end{array}\end{array}$

2. Describe your experience in the program? Was it positive/negative? Why? Please explain.

3. What would you say you got out of participating in a program like this? Please list any benefits.

4. What would you change about the Squat-n-Swap program to help it be more effective? 
5. How confident do you feel that you could continue to exercise regularly in this way (with the support of other like mothers) after the program's completion? Please explain why.

6. How did your children feel about the program?

7. How enjoyable/not enjoyable did you find the workouts to be? Why?

8. Other thoughts/comments?

9. How effective was the researcher in conducting informational workshops and exercise classes?

10. If you think another program design would be more beneficial for mothers of young children (e.g., in home), please describe. 


\title{
Appendix E
}

\section{Informed Consent Form for Treatment Participants}

\section{CONSENT TO PARTICIPATE VOLUNTARILY IN A RESEARCH INVESTIGATION}

\author{
Department of Physical Education, Health, and Recreation \\ Western Washington University \\ Bellingham, WA 98226
}

Responsible Faculty Member

Dr. Linda Keeler

(360) 650-3514

Participant's Name
Primary Researcher

Brook Skidmore, MS

(303) 564--0902

\section{PROJECT TITLE: THE SQUAT-N-SWAP: A PILOT EXERCISE INTERVENTION TO PROMOTE INCREASED PHYSICAL ACTIVITY AMONG MOTHERS OF YOUNG CHILDREN}

You are being asked to participate in a research investigation as described in this form below. All such investigational projects carried out within this department are governed by the regulations of both the Federal Government and Western Washington University. These regulations require that the investigator obtain from you a signed agreement (consent) to participate in this project. Your participation in this study is completely voluntary, and you may drop out at any time without penalty.

The purpose of this research project is to investigate the effects of a "Squat-n-Swap" exercise program on physical activity levels and perceived social support for exercise among mothers of young children. The study will consist of pre- and post-intervention questionnaires, and an exercise intervention lasting eight weeks. Participants will meet with a certified personal trainer one time per week at a designated church building. Mothers may bring their children with them to each exercise session. At each workout, half of the mothers will participate in a circuitstyle aerobic/resistance training workout with the exercise instructor. Each workout will last approximately 40 minutes. At this time, the other half of the mothers will watch the children, in essence, engaging in a "play date." At the end of the 40-minute workout, the two groups of mothers will switch, so that the previously exercising mothers then enjoy a play date with the children, and vice versa. For the first four weeks, participants will meet with the exercise 
instructor at each workout. In an effort to encourage adherence to the program, for the following four weeks, participants will continue to meet with their exercise group, but without the supervision of the exercise instructor. During this time, the exercise instructor will still be available to contact regarding any questions or concerns that arise with the exercise sessions.

All participants will receive a hard copy of the exercise routine (with pictures) to use as a reminder and guide during each exercise session. The exercise routine is easily adaptable for women at any fitness level, and modifications will be made on an individual basis to make the workout more or less strenuous, as needed. The exercise routine will be designed to enhance physical and mental health, and will target all major muscle groups of the body, including the core musculature. The researcher will provide a copy of the exercise protocol.

Your participation in this project will entail completion of a pre- and post-intervention questionnaire packet (approximately 20 minutes), and participation in one Squat-n-Swap exercise session per week (approximately 90 minutes total per week) for eight weeks. Participants will be encouraged to workout on their own on days they are not involved in the study. All information provided on research questionnaires will be held in strict confidentiality, and no names will be attached to any information provided by the participants. The signed informed consent forms will be stored in a locked file cabinet accessible only to the primary researcher.

There are many benefits that participants can expect to obtain by participating in this study. Participants will receive an exercise resistance band to use for the duration of the study, and to keep once they have finished. In addition, participants will benefit from participation in a group exercise class led by an experienced group exercise leader, a class for which individuals are typically charged in other fitness settings. Also, by exercising and socializing with other mothers, participants in this study will be able to obtain a social play date, in addition to their own exercise session. In addition, participants will have the opportunity to experience a new fitness routine, which can often serve as a new, fun challenge, and can be performed in a multitude of practical settings, such as the home, a park, or the backyard. Finally, participants will benefit physically and psychologically from a planned exercise program, with the numerous, well-known health benefits that accompany regular exercise.

Although there will be potential for some risk of injury during the study, the risk of injury will be no different than if the subject were to engage in similar exercise elsewhere. The possible risks involved with participation in this investigation are muscle soreness, fatigue, elevated heart rate. To minimize these risks, the subject will complete a Physical Activity Readiness Questionnaire prior to participation and will inform the test administrator of any physical disabilities. In addition, participants will always perform a proper warm-up and cool-down within each workout, they will adhere to all safety guidelines and technique instructions, and finally, participants will be responsible for immediately informing the training administrator of any negative feelings or symptoms that may arise at any time during the investigation. The data obtained from each subject will be held confidential. Finally, all training sessions for the first four weeks will be held under the supervision of an individual who is CPR/AED certified. 
Should an unforeseen physical injury occur, appropriate first aid will be provided, but no financial compensation will be given. In the event that a subject suffers any research-related injuries or adverse effects as a result of participation in the study, please contact the primary researcher listed above, and/or the RCO listed subsequently. Further information concerning your rights as a research participant can be obtained from Janai Symons, Research Compliance Officer (RCO), at (360) 650-3082.

All participants who sign this form will receive a copy of the consent form.

I CERTIFY THAT I HAVE READ AND FULLY UNDERSRTAND THE ABOVE PROJECT. I WILLINGLY CONSENT TO PARTICIPATE.

I am at least 18 years of age (please circle): Yes/No

Signature of Subject

Date 


\title{
Appendix F
}

\section{Informed Consent Form for Control Participants}

\section{CONSENT TO PARTICIPATE VOLUNTARILY IN A RESEARCH INVESTIGATION}

\author{
Department of Physical Education, Health, and Recreation \\ Western Washington University \\ Bellingham, WA 98226
}

Responsible Faculty Member

Dr. Linda Keeler

(360) 650-3514

Subject's Name
Primary Researcher

Brook Skidmore, MS

(303) 564--0902

\section{PROJECT TITLE: THE SQUAT-N-SWAP: A PILOT EXERCISE INTERVENTION TO PROMOTE INCREASED PHYSICAL ACTIVITY AMONG MOTHERS OF YOUNG CHILDREN}

You are being asked to participate in a research investigation as described in this form below. All such investigational projects carried out within this department are governed by the regulations of both the Federal Government and Western Washington University. These regulations require that the investigator obtain from you a signed agreement (consent) to participate in this project. Your participation in this study is completely voluntary, and you may drop out at any time without penalty.

The purpose of this research project is to investigate the effects of a "Squat-n-Swap" exercise program on physical activity levels and perceived social support for exercise among mothers of young children. The study will consist of pre- and post-intervention questionnaires, and an exercise intervention lasting eight weeks. Participants will meet with a certified personal trainer two times, once at the beginning of the eight-weeks, and once at the end of the eight weeks. Following this eight-week period, all participants will be offered the opportunity to learn about the Squat-n-Swap exercise protocol, and will be assisted in setting up the program to use for themselves. All participants will receive a free exercise resistance band, as well as a hard copy of the exercise routine (with pictures) to use as a reminder and guide for their future exercise sessions. The exercise routine is easily adaptable for women at any fitness level, and modifications can be made on an individual basis to make the workout more or less strenuous, as 
needed. The exercise routine will be designed to enhance physical and mental health, and will target all major muscle groups of the body, including the core musculature.

Your participation in this project will entail completion of a pre- and post-intervention questionnaire packet (approximately 20 minutes). Participants will be encouraged to maintain their current level of activity throughout the duration of the study. All information provided on research questionnaires will be held in strict confidentiality, and no names will be attached to any information provided by the participants. The signed informed consent forms will be stored in a locked file cabinet accessible only to the primary researcher.

There are many benefits that participants can expect to obtain by participating in this study. Participants will benefit from learning an exercise routine led by an experienced group exercise leader, a service for which individuals are typically charged in other fitness settings. Also, by exercising and socializing with other mothers, participants in this study will be able to learn a technique to effectively incorporate these two activities into their daily lives. In addition, participants will have the opportunity to experience a new fitness routine, which can often serve as a new, fun challenge, and can be performed in a multitude of practical settings, such as the home, a park, or the backyard. Finally, participants will benefit physically and psychologically from the introduction of an exercise program, with the numerous, well-known health benefits that accompany regular exercise.

Although there will be potential for some risk of injury during the study, the risk of injury will be no different than if the subject were to engage in similar exercise elsewhere. The risk of injury during the completion of the questionnaires is miniscule, and the possible risks involved with participation in introduction of the exercise routine (if the subject chooses to participate in this portion) are also minimal, and include muscle soreness, fatigue, and elevated heart rate. To minimize these risks, the subject will complete a Physical Activity Readiness Questionnaire prior to participation and will inform the test administrator of any physical disabilities. In addition, participants will always perform a proper warm-up and cool-down within each workout, they will adhere to all safety guidelines and technique instructions, and finally, participants will be responsible for immediately informing the training administrator of any negative feelings or symptoms that may arise at any time during the workout instruction. The data obtained from each subject will be held confidential. Finally, all training sessions will be held under the supervision of an individual who is CPR/AED certified.

Should an unforeseen physical injury occur, appropriate first aid will be provided, but no financial compensation will be given. In the event that a subject suffers any research-related injuries or adverse effects as a result of participation in the study, please contact the primary researcher listed above, and/or the RCO listed subsequently. Further information concerning your rights as a research subject can be obtained from Janai Symons, Research Compliance Officer (RCO), at (360) 650-3082.

All participants who sign this form will receive a copy of the consent form.

Finally, as an incentive to participate, participants will be given the chance to enter their names into a drawing for one of two $\$ 50$ gift cards to Babies ' $R$ Us. 


\section{CERTIFY THAT I HAVE READ AND FULLY UNDERSRTAND THE ABOVE PROJECT.} I WILLINGLY CONSENT TO PARTICIPATE.

I am at least 18 years of age (please circle): Yes/No

Signature of Subject

Date 


\section{Appendix G}

\section{Recruitment Email for Treatment Group}

Attention all mothers of young children!

Did you know that regular physical activity has been associated with reduced stress, improved selfesteem, increased energy, and even the ability to be a better parent? Are you currently reaping these benefits, and countless others that come from participating in a regular program of physical activity?

Research suggests that women, and specifically mothers of young children, are not physically active enough to obtain the abundant physical and mental health benefits that exercise has to offer. And I know what you're thinking, "Yeah right, I know exercise is good for me, but what mother has the time and energy for it??!!"

I am conducting an 8-week research study as part of my master's thesis that seeks to promote regular physical activity among mothers of young children. The exercise program is modifiable for all levels, even if you are brand new to exercise. The goals of the program include increased social support for exercise, enhanced exercise adherence skills, and increased overall exercise behavior. Additional positive side effects may include overall physical health and fitness levels.

Those who desire to participate may expect to receive the following benefits:

-Personal instruction in completing a safe and effective exercise program that can be completed virtually anywhere, including your own home. This instruction will be delivered by myself, a certified personal trainer and experienced group exercise leader, at no cost to you.

-Learning strategies that are specifically applicable to mothers of young children for fitting regular physical activity into an impossibly busy schedule. And no, it is not truly impossible! Childcare, again at no cost to you, is an embedded component of the program.

-Increased social support and encouragement from other mothers striving toward the same goal. -A free resistance band, yours to keep during and after completion of the study. -A convenient and private location in which to exercise.

Additional potential benefits include:

-Improved mental health and well-being, including better mood, improved body image, decreased stress and anxiety, and more energy.

-The ability to respond better to your family's needs, to react with less irritability to your children, to give more and do more.....in essence, to be an even better parent!

-Being a positive role model of healthy living for your children.

I know that being a mother requires constant sacrifice and service to those we love. A mother's life is not without busy schedules, challenging demands, and a never-ending to-do list. Because of this, mothers are probably the exact individuals who could benefit most from a program of regular physical activity! 


\section{Eligibility Questions}

\section{If you answer....}

\begin{tabular}{|c|c|}
\hline ...."YES" to all of these questions: & ....and "NO" to all of these questions: \\
\hline $\begin{array}{l}\text { 1. Do you have at least one child under the age of } \\
\mathbf{5} \text { ? Y/N } \\
\text { 2. Are YOU the primary caregiver of your } \\
\text { children? Y/N }\end{array}$ & $\begin{array}{l}\text { 1. Has your doctor ever said that you have a heart } \\
\text { condition and that you should only do physical } \\
\text { activity recommended by a doctor? Y/N } \\
\text { 2. Do you feel pain in your chest when you do } \\
\text { physical activity? Y/N } \\
\text { 3. In the past month, have you had chest pain when } \\
\text { you were not doing physical activity? Y/N } \\
\text { 4. Do you lose your balance because of dizziness or } \\
\text { do you ever lose consciousness? Y/N } \\
\text { 5. Do you have a bone or joint problem (for } \\
\text { example, back, knee or hip) that could be made } \\
\text { worse by a change in your physical activity? Y/N } \\
\text { 6. Is your doctor currently prescribing drugs (for } \\
\text { example, water pills) for your blood pressure or } \\
\text { heart condition? Y/N } \\
\text { 7. Do you know of any other reason why you } \\
\text { should not do physical activity? Y/N } \\
\text { 12. Are you currently engaging in a regular } \\
\text { program of exercise (consistently exercising at least } \\
\text { 150 min/week of moderate physical activity, or } 75 \\
\text { min/week of vigorous physical activity?) Y/N } \\
\text { 13. Have you been involved in a program of regular } \\
\text { exercise within the last } 6 \text { months (you have been } \\
\text { performing some sort of planned physical activity } \\
\text { consistently each week for at least } 3 \text { days/week, } \\
\text { with the purpose of improving physical and/or } \\
\text { mental health)? Y/N } \\
\text { 14. Are you currently pregnant, or is there any } \\
\text { chance you could be pregnant? Y/N }\end{array}$ \\
\hline
\end{tabular}


IF YOU QUALIFY FOR PARTICIPATION, PLEASE REPLY TO ME AT THIS EMAIL (skidmob@students.wwu.edu) for further details.

***The study will begin on JULY 1, 2014 with limited availability so act now! Why wait?*** 


\section{Appendix H}

\section{Recruitment Email for Control Group}

Attention all mothers of young children!

Research suggests that women, and specifically mothers of young children, are not physically active enough to obtain the abundant physical and mental health benefits that exercise has to offer. I am conducting an 8-week research study as part of my master's thesis that seeks to understand how to promote regular physical activity among mothers of young children. Your participation in the study will simply include completing a questionnaire now, and again in 8 weeks. The questionnaire takes about 20 minutes to complete.

As a token of appreciation for your participation, your name will be placed in a drawing to receive one of two $\$ 50$ gift cards to Babies 'R Us! In addition, at the conclusion of 8 weeks you will have the opportunity to participate in a free demonstration of an exercise program designed specifically for mothers of young children. If you choose to participate in this optional demonstration, you will receive a personal handout that includes pictures of the components of the exercise program, as well as a free exercise resistance band, yours to keep at the completion of the study.

\section{Eligibility Questions}

\section{If you answer....}

\begin{tabular}{|l|l|}
\hline ....YES" to all of these questions: & ....and "NO" to all of these questions: \\
\hline $\begin{array}{l}\text { 1. Do you have at least one child under the } \\
\text { age of 5? Y/N }\end{array}$ & $\begin{array}{l}\text { 1. Has your doctor ever said that you have a } \\
\text { heart condition and that you should only do } \\
\text { physical activity recommended by a doctor? } \\
\text { Y/N Are YOU the primary caregiver of your } \\
\text { children? Y/N }\end{array}$ \\
& $\begin{array}{l}\text { 2. Do you feel pain in your chest when you do } \\
\text { physical activity? Y/N }\end{array}$ \\
& $\begin{array}{l}\text { 3. In the past month, have you had chest pain } \\
\text { when you were not doing physical activity? } \\
\text { Y/N }\end{array}$ \\
& $\begin{array}{l}\text { 4. Do you lose your balance because of } \\
\text { dizziness or do you ever lose consciousness? } \\
\text { Y/N }\end{array}$ \\
& $\begin{array}{l}\text { 5. Do you have a bone or joint problem (for } \\
\text { example, back, knee or hip) that could be made } \\
\text { worse by a change in your physical activity? }\end{array}$ \\
\hline
\end{tabular}




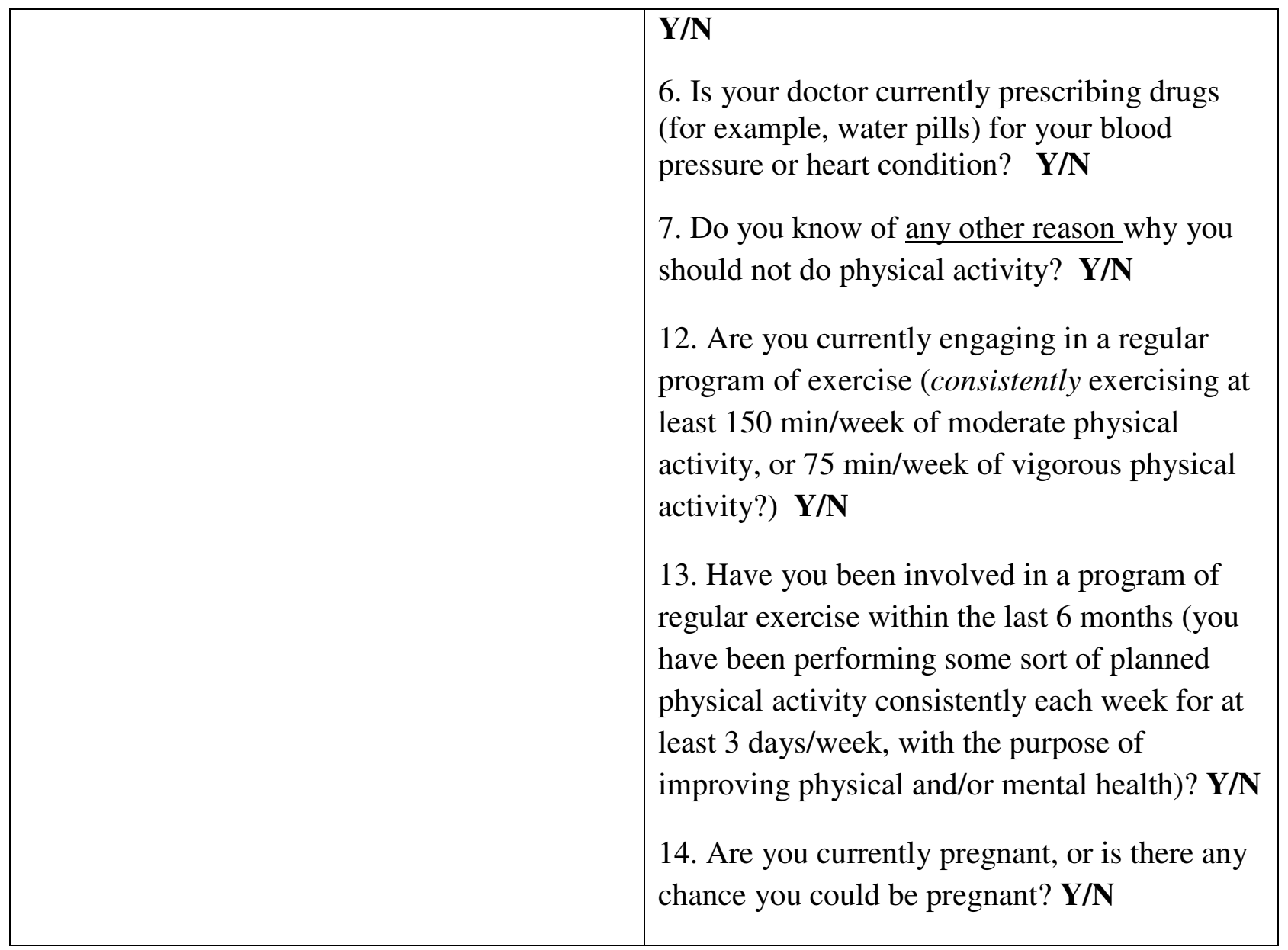

...you ARE ELIGIBLE to participate!

IF YOU QUALIFY FOR PARTICIPATION, PLEASE REPLY TO ME AT THIS EMAIL, (skidmob@students.wwu.edu) for further details. 


\section{Appendix I}

\section{Outline for Treatment Group Introductory Workshop}

I. Thank you for coming, and thank you for your participation! Introduce myself and my credentials.

II. Have all women complete questionnaire packet.

III. Discussion of benefits of regular physical activity for women, and for mothers of young children in particular. Explanation of potential benefits of their participation in this study. IV. Describe how the program will run each week.

V. Allow women to mingle and choose groups of 4-7 women. (Researcher will facilitate the formation of groups.) At this time each group should exchange contact information.

a. Discuss any special needs of children, and number of children each woman is expecting to bring to each exercise class.

b. Discuss what materials each woman can bring to help entertain the children (i.e., toys, puzzles, movies, games, snacks, etc.)

c. Establish a specific day and time that each group is capable of meeting with the researcher. (This requires a 90-minute commitment one time per week.) VI. Address any questions or concerns the women might have.

a. For example, "What happens if you become pregnant during the study?" (In order to continue participation, the woman must receive written permission from her doctor to continue.)

b. Remind women to bring a towel, water, and a light snack for herself. 


\section{Appendix J}

\section{Outline of Workout for Exercise Intervention}

WARM-UP: $10 \mathrm{BW}$ squats, 10 skips, 10 jumping jacks (or no-impact jacks), 10 high knee jogs, 10 butt kicks, $10 \mathrm{FW}$ lunges w/ twist RIGHT leg forward, 10 repeat LEFT, 10 pushups (on knees is fine), 10 donkey kicks, 10 good mornings, 10 hand claps!

WORKOUT

*NOTE: Participants were encouraged to listen to their bodies. When needed, modifications were given to allow for safe, pain-free movements, and enhanced enjoyment of the workout.

The following circuit was repeated two times with a brief water break in between each set. Each exercise was performed for 30 seconds before immediately moving on the next exercise.

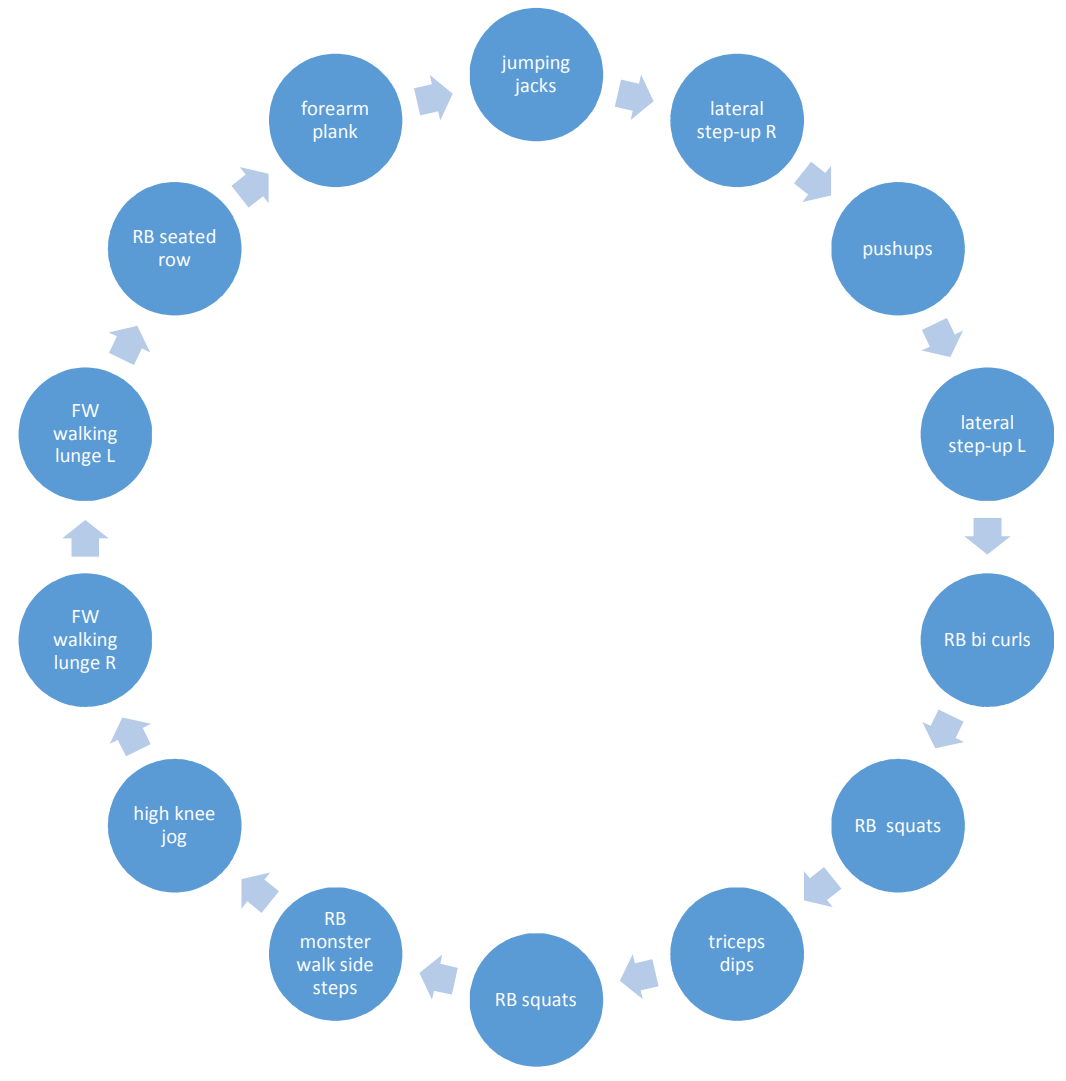

\section{CORE WORK AND STRETCHING}




\section{Appendix K}

\section{Outline of Exercise Psychology Principles Discussed during Cooldown Portion of Workouts}

\section{Identifying sources of social support}

a. Ask who they perceive as potential sources of support in their exercise goals

-Family, friends, neighbors, daycare facilities, babysitters, others?

-Instrumental support; emotional support; companionship support

b. Ask what types of informational support they perceive available to them

-Exercise leaders, media, physicians, others?

c. Ask who they perceive as validating supporters in their lives (women in similar situations)

d. Discuss each of these areas and why they might prove beneficial in encouraging regular exercise

e. Explore previously unidentified sources of social support

\section{Prioritizing exercise}

a. Discuss what they perceive are the benefits they gain from regular exercise

b. Discuss perceived barriers to exercise

c. Discuss why these might be perceptions, and not truly barriers to exercise

d. Discuss alternative options to overcome these barriers

e. Negotiating constraints (Henderson \& Bialeschki, 1993; Shaw et al., 1991)

\section{Ethic of care}
a. Define
b. Discuss her association with this ideology
c. Discuss how regular exercise might assist her in her role as a mother

\section{Cognitive reframing}

a. Revisit the ethic of care discussion

b. Brainstorm ways an exercising mother could reframe potential thoughts of guilt and selfishness to instead reflect ways she is in fact taking even better care of her family by exercising regularly 